

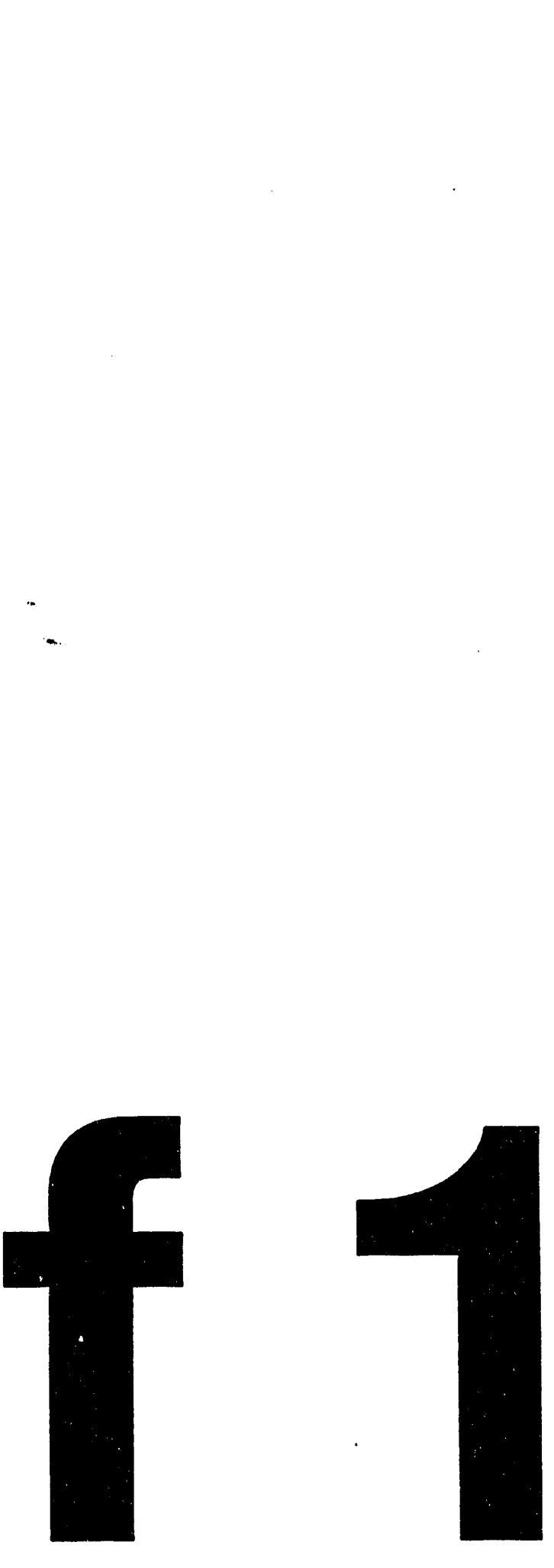


UCRL-CR-115942

S/C-B171242

Final Report on Spectral Broadening by Cross-Phase Modulation in Linearly Birefringent Optical Fibers

\author{
C.- J. Chen \\ P. K. A. Wai \\ C. R. Menyuk
}

University of Maryland

Department of Electrical Engineering

December 1993

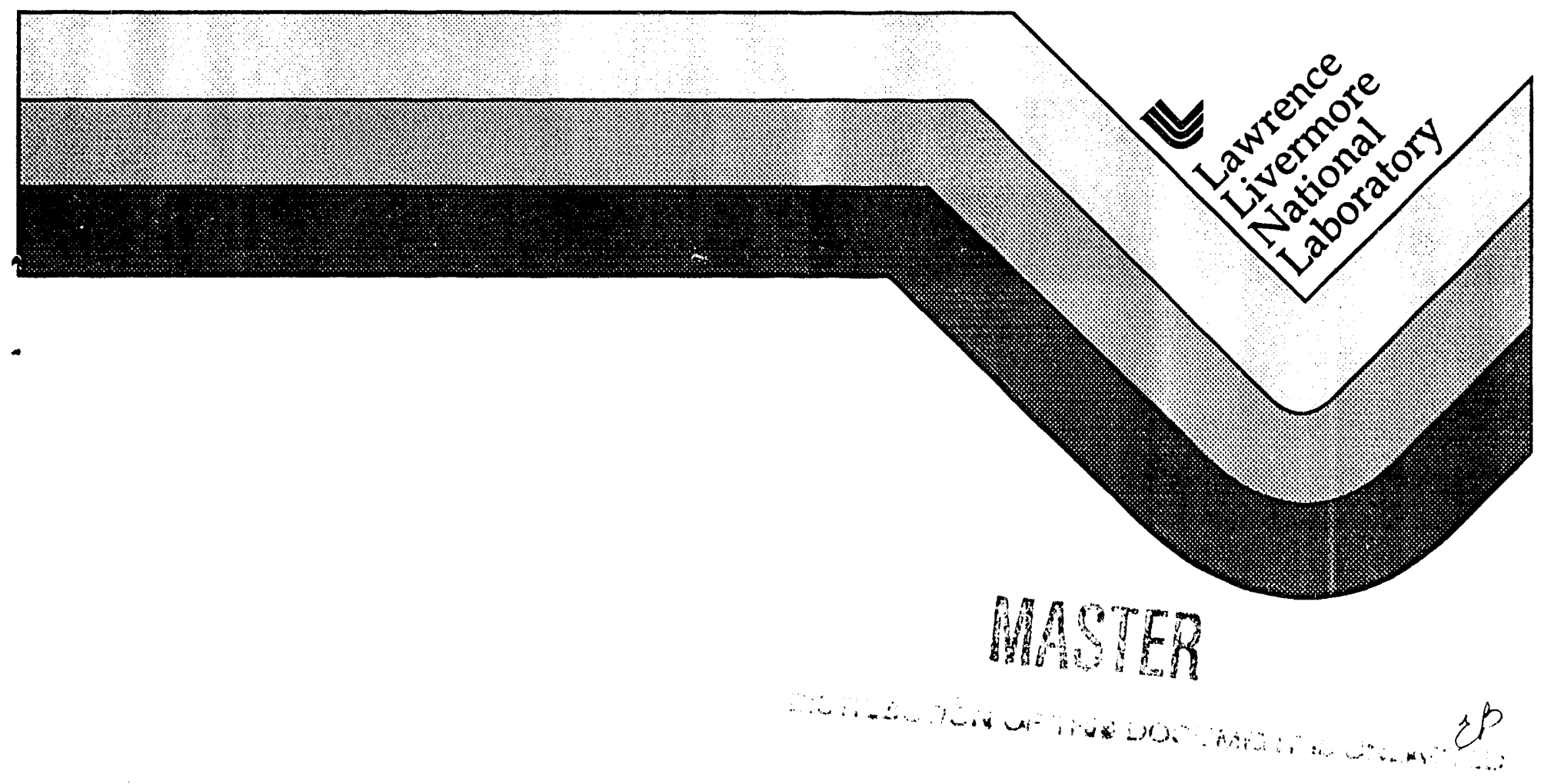


DISCLAINIER

Work performed under the auspices of the U.S. Department of Energy by Lawrence Livermore National Laboratory under contract number W-7405-E.VG-48.

This document was prepared as an account of work sponsored by an agency of the United States Government. Neither the United States Government nor the University of California nor any of their employees. makes any warranty, express or implied, or assumes any legal liability or responsibility for the accuracy, completeness, or usefulness of any information, apparatus, product, or process disclosed, or represents that its use would not infringe privately owned rights. Reference herein to any specific commercial products, process, or service by trade name. trademark, manufacturer, or otherwise, does not necessarily constitute or imply its endorsement, recommendation. or favoring by the United States Government or the Lniversity of California. The vieus and opinions of authors expressed herein do not necessarily state or reflect those of the Lnited States Government or the University of California, and shall not be used for advertising or product endorsement purposes. 


\title{
Final Report on Spectral Broadening by Cross-Phase Modulation in Linearly Birefringent Optical Fibers
}

\author{
by \\ C.-J. Chen, P. K. A. Wai, and C. R. Menyuk \\ Department of Electrical Engineering, University of Maryland \\ Baltimore, MD 21228-5398
}

\begin{abstract}
Spectral widening by using the cross-phase modulation in a linearly birefringent optical fiber is investigated numerically. The coupled nonlinear Schrödinger equation that describes the wave propagation of each polarization in a birefringent optical fiber is discussed. Based on this equation, we generated computer simulations for different values of birefringence and dispersion. We found that a smooth output signal with intensity fluctuations of less than $10 \%$ and a spectral width of more than $50 \AA$ is possible with low dispersion and low birefringence, e.g., $D=-10 \mathrm{psec} / \mathrm{nm}-\mathrm{km}$ and $\Delta n=2 \times 10^{-5}$. We also found that the Raman effect does not play an significant role.
\end{abstract}




\section{Introduction}

Spectral widening by using the cross-phase modulation in a birefringent optical fiber has been proposed and carried out at Lawrence Livermore National Laboratory. ${ }^{1,2}$ In these experiments, a broad band noisy pump beam and a narrow band smooth signal beam are launched into the two axes of a polarization maintaining fiber. Through cross-phase modulation, the intensity in one polarization axis of a fiber can affect the phase of the beam in the other axis, and vice versa. These phase variations induce a frequency shift which is then transformed into spectral broadening. When selfand cross-phase modulation dominate, the instantaneous frequency change is proportional to the time derivative of the optical intensity in the other axis. The spectral broadening of the signal beam which is in one axis depends on the statistical characteristics of the pump intensity, which is in the other axis, so that spectral broadening of the signal beam is proportional to the average intensity of the pump beam and the propagation distance. However, in most cases, complication arises because the signal beam changes shape as it propagates due to dispersion, birefringence, and the Raman effect. As a consequence, the signal beam develops undesirable intensity fluctuations.

In the interim report that we submitted in May, we showed preliminary simulation results, in which birefringence, dispersion, and the Raman effect are all taken into account. We demonstrated by a comparison between the simulations and experiments that the effective core area is 2.8 times the actual core area. We also noted that the Raman effect has only a minor effect on both spectral broadening and the location of the central frequency. 
In this report, based on the knowledge that we had before, we describe a matrix of simulation results for dispersion $D=-5,-10,-20$, and $-40 \mathrm{psec} / \mathrm{nm}-\mathrm{km}$ (normal dispersion) and birefringence $\Delta n=5,10,20,40$, and $80 \times 10^{-6}$. For low dispersion and low birefringence, it is possible to obtain $50 \AA$ over a short length of fiber. For example, a spectral width of $50 \AA$ is obtained when $D=-10 \mathrm{psec} / \mathrm{nm}-\mathrm{km}$, $\Delta n=20 \times 10^{-6}$, and the fiber length is $6 \mathrm{~m}$. We added the Raman effect to one run at each dispersion value and found no significant influence. For completeness, we include the formulation and results from the interim report.

\section{Basic Equations and Normalizations}

The equation that describes the wave evolution inside a birefringent optical fiber can be derived from Maxwell's equations by using the slowly varying envelope approximation. The two pulse profiles, $U$ and $V$, in the two polarization axes of the birefringent optical fiber satisfy ${ }^{3}$

$$
\begin{aligned}
& i \frac{\partial U}{\partial z}+i k^{\prime} \frac{\partial U}{\partial t}-\frac{1}{2} k^{\prime \prime} \frac{\partial^{2} U}{\partial t^{2}}+\frac{\omega_{0} n_{2}}{c}\left(|U|^{2}+B|V|^{2}\right) U=0 \\
& i \frac{\partial V}{\partial z}+i l^{\prime} \frac{\partial V}{\partial t}-\frac{1}{2} l^{\prime \prime} \frac{\partial^{2} V}{\partial t^{2}}+\frac{\omega_{0} n_{2}}{c}\left(B|U|^{2}+|V|^{2}\right) V=0
\end{aligned}
$$

when the Raman effect can be ignored, where $z$ is the propagation distance, $t$ is time, $\omega_{0}$ is the carrier angular frequency, and $c$ is the speed of light. The dispersion relations for the two axes are $k(\omega)$ and $l(\omega)$ respectively and $k^{\prime}=\partial k /\left.\partial \omega\right|_{\omega_{0}}, l^{\prime}=\partial l /\left.\partial \omega\right|_{\omega_{0}}$, $k^{\prime \prime}=\partial^{2} k /\left.\partial \omega^{2}\right|_{\omega_{0}}$, and $l^{\prime \prime}=\partial^{2} l /\left.\partial \omega^{2}\right|_{\omega_{0}}$. We will discuss the relevant numerical values shortly. The parameter $n_{2}$ is the Kerr coefficient. Its numerical value is $n_{2}=3.2 \times$ 
$10^{-20} \mathrm{~m}^{2} / \mathrm{W} .4$ The cross-phase modulation is represented by $B$, which is $2 / 3$ for a linearly birefringent optical fiber.

The Raman effect at one frequency is described in terms of the pump intensity and the Stokes intensity. They have the following relationship

$$
\frac{d I_{\mathrm{s}}}{d z}=G_{\mathrm{R}} I_{\mathrm{p}} I_{\mathrm{s}}
$$

where $I_{\mathrm{p}}$ and $I_{\mathrm{s}}$ are the pump and the Stokes intensities respectively. The coefficient $G_{\mathrm{R}}$ depends on the frequency difference between the pump and the Stokes waves and is proportional to the pump frequency, $\omega_{p}$. For an optical fiber made of fused silica, $G_{R}$ has a maximum value of $1.1 \times 10^{-13} \mathrm{~m} / \mathrm{W}$ at a frequency difference of 13.2 $\mathrm{THz}$ and a pump wavelength of $1 \mu \mathrm{m}$. If the bandwidths of the pulses are much less than $13.2 \mathrm{THz}, G_{\mathrm{R}}$ can be approximated by a linear function in the frequency domain, which corresponds to a first derivative in the time domain. ${ }^{4}$ In such an approximation, $G_{\mathrm{R}}=C_{\mathrm{R}} f$, where $f$ is the frequency difference and $C_{\mathrm{R}}$ is $8.3 \times 10^{-27}$ $\mathrm{m}-\mathrm{sec} / \mathrm{W}$ from the measured quantities above. Note that in a birefringent fiber, the perpendicular Raman response has to be taken into account. ${ }^{5}$ In the slowly varying envelope approximation mentioned above, the Raman contributions are included by adding terms at the end of each sub-equation,

$$
\begin{aligned}
& \left.i \frac{\partial U}{\partial z}\right|_{\text {Raman }}+\left(C_{1} U \frac{\partial|U|^{2}}{\partial t}+C_{2} U \frac{\partial|V|^{2}}{\partial t}+C_{3} V \frac{\partial U V^{\bullet}}{\partial t}\right)=0 \\
& \left.i \frac{\partial V}{\partial z}\right|_{\text {Raman }}+\left(C_{1} V \frac{\partial|V|^{2}}{\partial t}+C_{2} V \frac{\partial|U|^{2}}{\partial t}+C_{3} U \frac{\partial V U^{\star}}{\partial t}\right)=0
\end{aligned}
$$

where $C_{1}=C_{\mathrm{R}} / 2$ is for the parallel Raman effect and $C_{2}$ and $C_{3}$, whose values are both equal to $C_{1} / 3$, are for the perpendicular Raman effect. ${ }^{6}$ 
The complete equation is the combination of Eq. (1) and Eq. (3). Normalization of the equation is convenient for doing numerical simulations. We carry out the normalization as follows. By setting new variables,

$$
s=\frac{t}{T}, \quad \xi=\frac{z}{Z}, \quad u=\frac{U}{\sqrt{I}}, \quad v=\frac{V}{\sqrt{I}}
$$

and choosing $I=c / \omega_{0} n_{2} Z, T=1 \mathrm{psec}$, and $Z=1 \mathrm{~m}$, We obtain

$$
\begin{aligned}
& i \frac{\partial u}{\partial \xi}+i \delta \frac{\partial u}{\partial s}+\epsilon \frac{\partial^{2} u}{\partial s^{2}}+\left(|u|^{2}+\frac{2}{3}|v|^{2}\right) u+c_{1} u \frac{\partial|u|^{2}}{\partial s}+c_{2} u \frac{\partial|v|^{2}}{\partial s}+c_{3} v \frac{\partial u v^{*}}{\partial s}=0 \\
& i \frac{\partial v}{\partial \xi}-i \delta \frac{\partial v}{\partial s}+\epsilon \frac{\partial^{2} v}{\partial s^{2}}+\left(\frac{2}{3}|u|^{2}+|v|^{2}\right) v+c_{1} v \frac{\partial|v|^{2}}{\partial s}+c_{2} v \frac{\partial|u|^{2}}{\partial s}+c_{3} u \frac{\partial v u^{*}}{\partial s}=0
\end{aligned}
$$

where $\delta=1.67 \times 10^{3} \Delta n$, and $\Delta n$ is the difference between the refractive indices of the two polarizations. The parameter $\epsilon=0.294 \times D$, where $D$ is the chromatic dispersion measured in $\mathrm{psec} / \mathrm{nm}-\mathrm{m}$. The intensity normalization $I$ has a value of $5.24 \mathrm{~W} / \mu \mathrm{m}^{2}$. The Raman coefficients are given $c_{1} / 3=c_{2}=c_{3}$ and $2 \pi c_{1}=1.86 \times 10^{-2} .6$

We solve Eq. (5) using a second order accurate beam propagation method. ${ }^{7}$ Given the initial pulse profiles, we calculate their evolution according to Eq. (5). The output profiles are further analyzed to obtain the power, the peak power/average power, the central frequency, and the spectral width of each polarization. The broadband pump has a spectral width of $450 \mathrm{GHz}$, which corresponds to 2 psec variations in the time domain, and the number of sampling points in the time domain must be large enough to resolve these structures. It is not practical to simulate entire pulses, which have durations of 10 nsec. Instead, we simulate a time slice by using a time window of several hundred picoseconds. 


\section{Numerical Simulations (from the Interim Re- port)}

In this section, we review the numerical simulations and the comparison with experiments previously described in the interim report. The emphasis in this section is upon determining the effective area of the experimental fiber and the importance of the Raman effect.

From the experimental results, ${ }^{1,2}$ we find the parameters that are needed in the numerical simulations. The wavelength used is $\lambda_{0}=1.053 \mu \mathrm{m}$. The refractive index difference used is $\Delta n=6 \times 10^{-5}$, and the dispersion used is $D=-0.04 \mathrm{psec} / \mathrm{nm}-\mathrm{m}$. The pulse energy of the signal is $1 \mu \mathrm{J}$ and the duration is 10 nsec. The broadband pulse has an energy of $5 \mu \mathrm{J}$, a duration of $15 \mathrm{nsec}$, and a spectral width of $450 \mathrm{GHz}$. In the simulation of this broadband noisy pump beam, we assume a random phase relation for all the modes. The fiber core size is $4 \mu \mathrm{m} \times 6 \mu \mathrm{m}$, or $24 \mu \mathrm{m}^{2}$. The optical intensity in each polarization can be obtained by calculating the ratio of pulse energy to pulse duration and then dividing by the effective core area, which is defined as

$$
A_{\mathrm{eff}}=\frac{\left(\int I d A\right)^{2}}{\int I^{2} d A}
$$

where $I$ is intensity and $A$ is area.

The effective core area is roughly twice the actual core area, ${ }^{8}$ but the exact value must be determined empirically. To do so, we carried out a series of simulations in which the Raman effect is neglected, i.e., $c_{1}=c_{2}=c_{3}=0$. Spectral broadening in both polarizations is then observed. As we increase the effective area relative to the 
measured area, we find that the intensity decreases and, hence, the spectral broadening decreases. The best agreement with the experiments was found when $A_{\text {eff }}=2.78$ $x$ the core area. This can be seen by reference to Table 1, which summarizes all the simulations which were previously included in the interim report.

In the simulated results, the analyzed data is followed by the pulse profiles and spectra of both polarizations. In the analyzed data, we calculate at various propagation distances the pulse intensity (Itsy), the peak intensity/average intensity (pk/avg), the central frequency (f cent), and the spectral width (fwidth). The definition of the last two quantities are:

$$
\begin{aligned}
\text { fcent } & =\frac{\int \omega|\tilde{u}(\omega)|^{2} d \omega}{\int|\tilde{u}(\omega)|^{2} d \omega} \\
\text { fwidth } & =2 \sqrt{2 \ln (2)}\left[\frac{\int \omega^{2}|\tilde{u}(\omega)|^{2} d \omega}{\int|\tilde{u}(\omega)|^{2} d \omega}-(\text { f cent })^{2}\right]^{1 / 2}
\end{aligned}
$$

where $\tilde{u}(\omega)$ represents the Fourier transform of a certain pulse profile $u$. The factor in the spectral width is the ratio of the FWHM width to the variance of a Gaussian function.

Simulated results are attached at the end of the report in the Appendix. Set \#1 corresponds to $A_{\text {eff }}=2.78 \times$ the core area. As the pulses in each polarization propagate down the fiber, their spectral widths increase. At the beginning of the propagation, the signal pulse broadens rapidly and tends toward a limiting value. Its intensity becomes nosier as it propagates because of the dispersion. Additionally, the frequency centroids of the two polarizations shift apart because the two polarizations are bound together throurch cross-phase modulation and their frequency centroids shift in the 
directions required to eliminate the velocity difference. The central frequency of the slow axis shifts down since in the normal dispersion regime lower frequencies travel faster. The pulse in the fast axis shifts correspondingly to higher frequency.

When the Raman effect is included in the simulations, the results are almost unchanged because the spectral widths of the pulses are small. The results are in Set \#2 for the same parameters as in Set \#1. A small fraction of power is transferred from the fast axis, which has a higher central frequency, to the slow axis as expected with the Raman effect, i.e., the higher frequency component pumps the lower frequency one. We also notice some additional frequency downshifts in both polarizations. Again, this result is expected with the Raman effect. 4

Twelve computer simulations using various effective areas, some of which include the Raman effect and some of which do not, are summarized in Table 1. For each simulation, we list the spectral widths as the fiber length increases. When the effective area equals $2.78 \times$ the actual area, the spectral broadening becomes comparable with the measured values. This value was determined by interpolation from runs 3 and 4 and was confirmed in run 5 in which the spectral widths are close to the experimental values. The measured values are obtained from the experimental data, 1,2 using $1 \AA=$ $27 \mathrm{GHz}$ (at $\lambda=1.053 \mu \mathrm{m}$ ). The Raman effect has only a slight effect as comparison of run nos. 2 and 5 to run nos. 3 and 6 shows. The attached Sets \#1 and \#2 correspond to run nos. 5 and 6 respectively. Three runs, nos. 7, 8, and 9, with effective areas 60,96 , and $120 \mu^{2}$ are included for reference. The dispersion of the fiber in run no. 10 is half of that of run no. 5 while the birefringence in run no. 11 is half of that 
of run no. 5. All other parameters are the same as those of run no. 5. In run no. 12 , both the dispersion and birefringence are half of that of run no. 5 . For all the propagation distances in runs no. 10,11, and 12, the spectral broadening is larger than the corresponding one in run no. 5. The spectral broadening also takes a longer distance to saturate when compare to that of run no. 5.

\section{Numerical Simulations (New Results)}

In this section, we describe the results which we have obtained since we submitted the interim report. The emphasis is upon determining the conditions under which it is possible to obtain $50 \AA$ of spectral width.

We carried out a matrix of simulations with $D=-5,-10,-20$, and $-40 \mathrm{psec} / \mathrm{nm}$ $\mathrm{km}$ (normal dispersion) and $\Delta n=5,10,20,40$ and $80 \times 10^{-6}$. We did four additional runs to check the impact of the Raman effect. In Table 2, we summarize these 24 runs of numerical simulation and list the output signal spectral widths. The effective core area in all these simulations is taken to be $66.72 \mu \mathrm{m}^{2}$, which is adopted from the results of the interim report and close to the effective core areas of most optical fibers.

In these simulations, we also analyze on the fluctuations of the signal pulses. The ratio of the signal intensity variation to its average intensity (var/avg) is calculated for each simulation. The definition is

$$
\operatorname{var} / \operatorname{avg}=\frac{\left(<|u(t)|^{4}>-<|u(t)|^{2}>^{2}\right)^{1 / 2}}{\left.<|u(t)|^{2}\right\rangle}
$$


where $\langle x\rangle=\int_{-x 1}^{x 1} x(t) d t / 2 \times 1$ and $2 \times 1$ is the window size of the simulation, which is 100 picoseconds. This ratio can be used as a measure of the fluctuation of the optical intensity.

We find that the signal spectral width decreases as birefringence increases under fixed dispersion. Since the walk-off effect increases for both polarizations at larger birefringence, the phase changes due to the cross phase modulation are relatively uniform because the noisy pump beam walks through the signal pulse. This averaging effect reduces the signal spectral width.

For fixed birefringence, spectral width decreases with increasing dispersion except when the birefringence is large $\left(\Delta=80 \times 10^{-6}\right)$. When dispersion is large, the change in shape of the optical beams due to dispersion becomes significant in both polarizations. The fluctuation in optical intensities also leads to a more uniform phase shift and hence reduces signal spectral width. However, high birefringence and therefore larger walk-off is expected to destroy the averaging effect of pulse shape fluctuation.

For the same spectral width, the signal beam is smoother at lower birefringence and lower dispersion. There are several instances in which the signal spectral widths exceed $50 \AA$, or $1350 \mathrm{Ghz}$, especially at low birefringence. At high birefringence, although $50 \AA$ is reachable, the signal suffers from too much fluctuation. To obtain $1350 \mathrm{Ghz}$, the var/avg is 0.068 at $4 \mathrm{~m}$ in run no. 1 , Table 2 ; while it is 0.524 at $8 \mathrm{~m}$ in run no. 16. Low dispersion and low birefringence improve the smoothness of the signal beam. In order to verify that the Raman effect has no impact on this results, 
we included the Raman effect in several cases which are listed in Table 2 as runs 21-24.

The main difficulty at low birefringence is that it is difficult to maintain a high polarization extinction ratio. Theoretically, the polarization extinction ratio can be arbitrarily high if there are no defects and twists in the fiber. Extinction ratios larger than $10 \mathrm{~dB}$ are possible over $100 \mathrm{~m}$ for birefringence as low as $1 \times 10^{-5}$ with careful handling of the fibers in the experiments so that they are free of twist and stress. ${ }^{9}$ Since the fiber length used is only a few meters, the birefringence may be decreased further while still maintaining a good extinction ratio.

\section{Conclusions}

We have formulated and studied numerically spectral broadening of optical pulses by using the cross phase modulation of a birefringent optical fiber. With low dispersion and low birefringence, one can obtain a smooth signal output with a spectral width of more than $50 \AA$. To do so, while maintaining a good polarization extinction ratio, one must use high quality fibers and handle them carefully.

\section{Acknowledgement}

The authors would like to thank Dr. R. H. Stolen of AT\&T Bell Laboratories for discussing with us achievable fiber parameters. 


\section{References}

[1] P. H. Chaffee, F. G. Patterson, and M. A. Henesian, in Conference on Lasers and Electro-Optics (Optical Society of America, Washington, D. C., 1989), paper WD 3.

[2] H. T. Powell, S. N. Dixit, and M. A. Henesian, Inertial Confinement Fusion Quarterly Report 1, 28 (1990).

[3] C. R. Menyuk, IEEE J. Quantum Electron. QE-25, 2674 (1989).

[4] J. P. Gordon, Opt. Lett. 11, 662 (1986).

(5] C. R. Menyuk, M. N. Islam, and J. P. Gordon, Opt. Lett. 16, 566 (1991).

[6] C.-J. Chen, C. R. Menyuk, M. N. Islam, and R. H. Stolen, Opt. Lett. 16, 1647 (1991).

[7] C. R. Menyuk, Opt. Lett. 12, 614 (1987).

[8] A. H. Hasegawa and Y. Kodama, Proc. IEEE 69, 1145 (1981).

[9] R. H. Stolen, private communication. 


\begin{tabular}{|c|c|c|c|c|c|}
\hline $\begin{array}{l}\text { Run } \\
\text { No. }\end{array}$ & $\begin{array}{l}\text { effective } \\
\text { area } \mu \mathrm{m}^{2}\end{array}$ & $\begin{array}{c}\text { Raman } \\
\text { included }\end{array}$ & $\begin{array}{l}\text { Propagation } \\
\text { distance }(m)\end{array}$ & $\begin{array}{c}\text { Spectral width } \\
\text { of the signal }(\mathrm{GHz})\end{array}$ & Comment \\
\hline \multirow[t]{8}{*}{$\overline{1}$} & \multirow[t]{8}{*}{$\overline{24}$} & \multirow[t]{8}{*}{$\overline{\mathrm{No}}$} & $\overline{1.5}$ & 1091.0 & \\
\hline & & & 3.0 & 1372.9 & \\
\hline & & & 4.5 & 1604.6 & \\
\hline & & & 6.0 & $\overline{1727.4}$ & \\
\hline & & & 7.5 & 1872.2 & \\
\hline & & & 9.0 & 2005.1 & \\
\hline & & & 10.5 & 2072.7 & \\
\hline & & & 12.0 & 2108.6 & \\
\hline \multirow[t]{8}{*}{$\overline{2}$} & \multirow[t]{8}{*}{$\overline{48}$} & \multirow[t]{8}{*}{ No } & 1.5 & 707.2 & \\
\hline & & & 3.0 & 959.4 & \\
\hline & & & 4.5 & 1063.9 & \\
\hline & & & 6.0 & 1151.4 & \\
\hline & & & 7.5 & 1293.9 & \\
\hline & & & 9.0 & 1430.7 & \\
\hline & & & 10.5 & 1489.9 & \\
\hline & & & 12.0 & 1530.6 & \\
\hline \multirow[t]{8}{*}{3} & \multirow[t]{8}{*}{48} & \multirow[t]{8}{*}{$\overline{\text { Yes }}$} & $\overline{1.5}$ & $\overline{707.5}$ & \multirow{8}{*}{$\begin{array}{l}\text { Compared with run no. 2, the } \\
\text { Raman effect does not signifi- } \\
\text { cantly change the spectral } \\
\text { widths. }\end{array}$} \\
\hline & & & 3.0 & 960.2 & \\
\hline & & & 4.5 & 1065.6 & \\
\hline & & & 6.0 & 1159.5 & \\
\hline & & & 7.5 & 1312.2 & \\
\hline & & & 9.0 & 1458.1 & \\
\hline & & & 10.5 & 1528.4 & \\
\hline & & & 12.0 & 1595.4 & \\
\hline \multirow[t]{8}{*}{4} & \multirow[t]{8}{*}{72} & \multirow[t]{8}{*}{$\overline{\text { No }}$} & 1.5 & $\overline{500.0}$ & \\
\hline & & & 3.0 & 757.7 & \\
\hline & & & 4.5 & 844.3 & \\
\hline & & & 6.0 & 885.9 & \\
\hline & & & 7.5 & $\overline{934.1}$ & \\
\hline & & & 9.0 & 1000.4 & \\
\hline & & & 10.5 & 1074.8 & \\
\hline & & & 12.0 & 1159.7 & \\
\hline \multirow[t]{8}{*}{$\overline{5}$} & \multirow[t]{8}{*}{66.72} & \multirow[t]{8}{*}{$\overline{\text { No }}$} & $\overline{1.5}$ & $\overline{535.1}$ & \\
\hline & & & $\overline{3.0}$ & 793.9 & $811.7 \mathrm{GHz}$ (Measured) \\
\hline & & & 4.5 & 882.7 & \\
\hline & & & 6.0 & 939.9 & $947.0 \mathrm{GHz}$ (Measured) \\
\hline & & & 7.5 & 1036.5 & \\
\hline & & & 9.0 & 1106.9 & \\
\hline & & & 10.5 & 1206.3 & $1217.5 \mathrm{GHz}$ (Measured) \\
\hline & & & 12.0 & 1302.7 & \\
\hline \multirow[t]{8}{*}{$\overline{\overline{6}}$} & \multirow[t]{8}{*}{66.72} & \multirow[t]{8}{*}{$\overline{\overline{Y e s}}$} & 1.5 & $\overline{535.2}$ & \multirow{8}{*}{$\begin{array}{l}\text { Again, the spectral widths } \\
\text { are not significantly changed } \\
\text { by the Raman effect. }\end{array}$} \\
\hline & & & 3.0 & 794.6 & \\
\hline & & & 4.5 & 883.3 & \\
\hline & & & 6.0 & 940.0 & \\
\hline & & & 7.5 & 1038.5 & \\
\hline & & & 9.0 & 1113.6 & \\
\hline & & & 10.5 & 1220.9 & \\
\hline & & & 12.0 & 1325.8 & \\
\hline
\end{tabular}



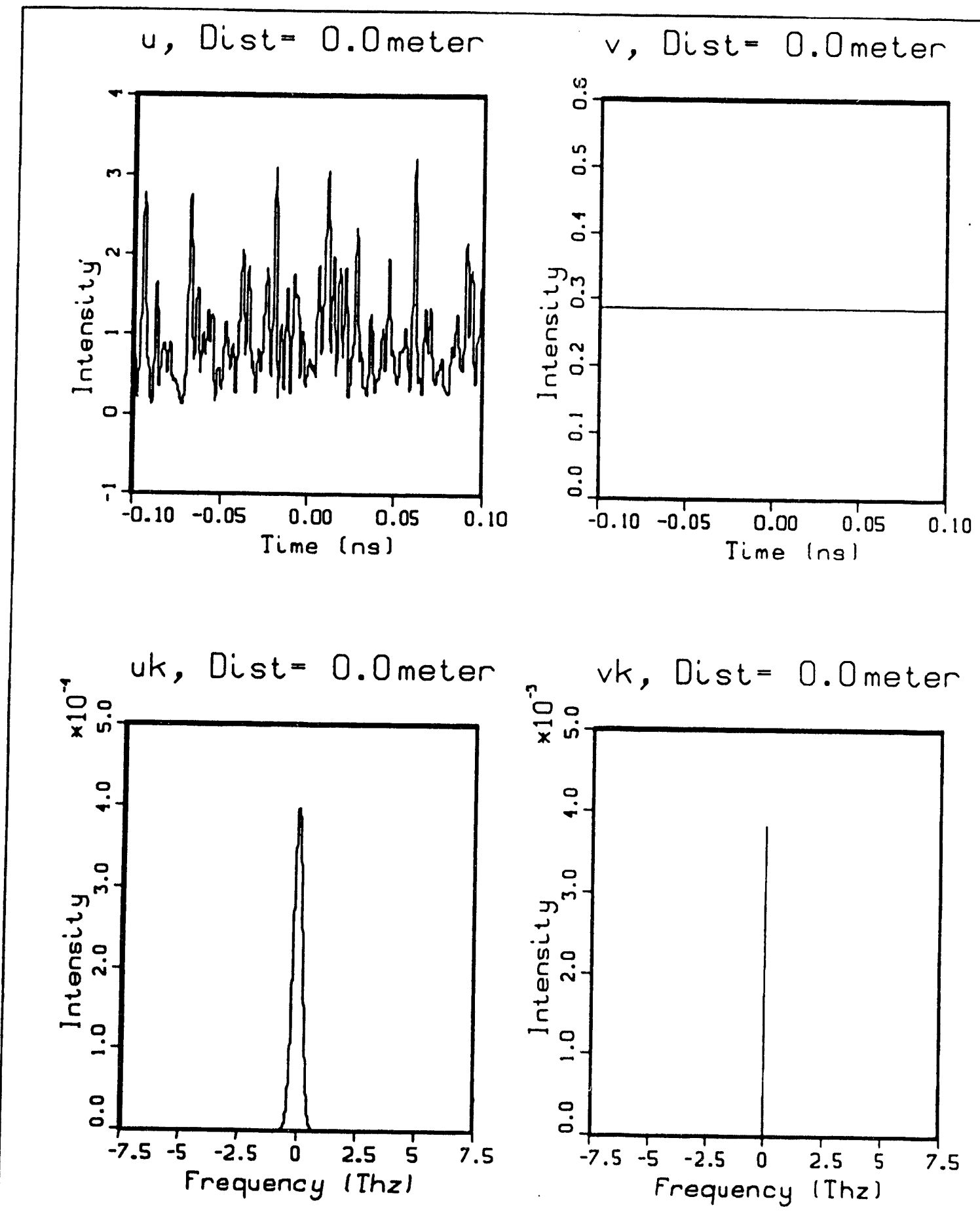


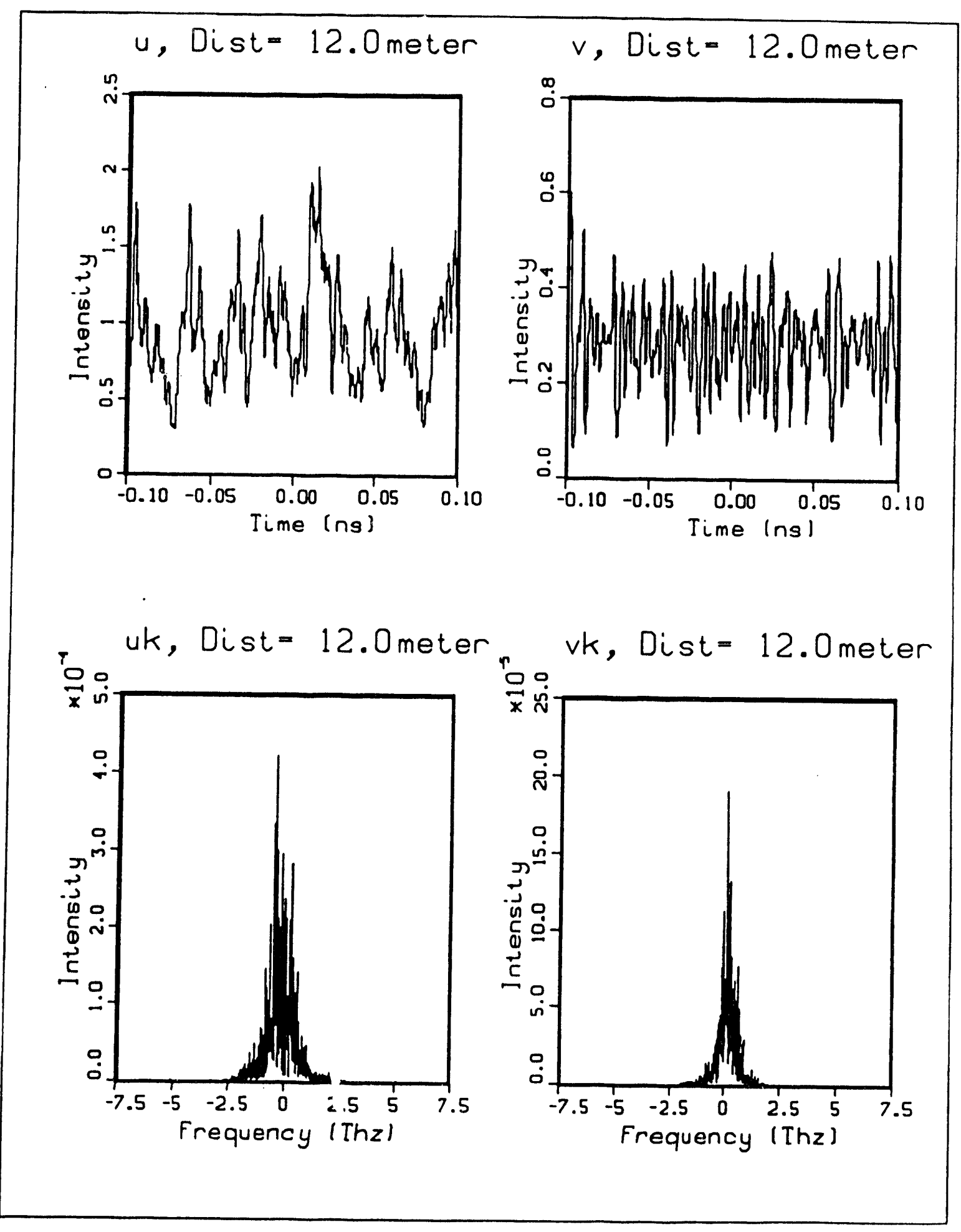




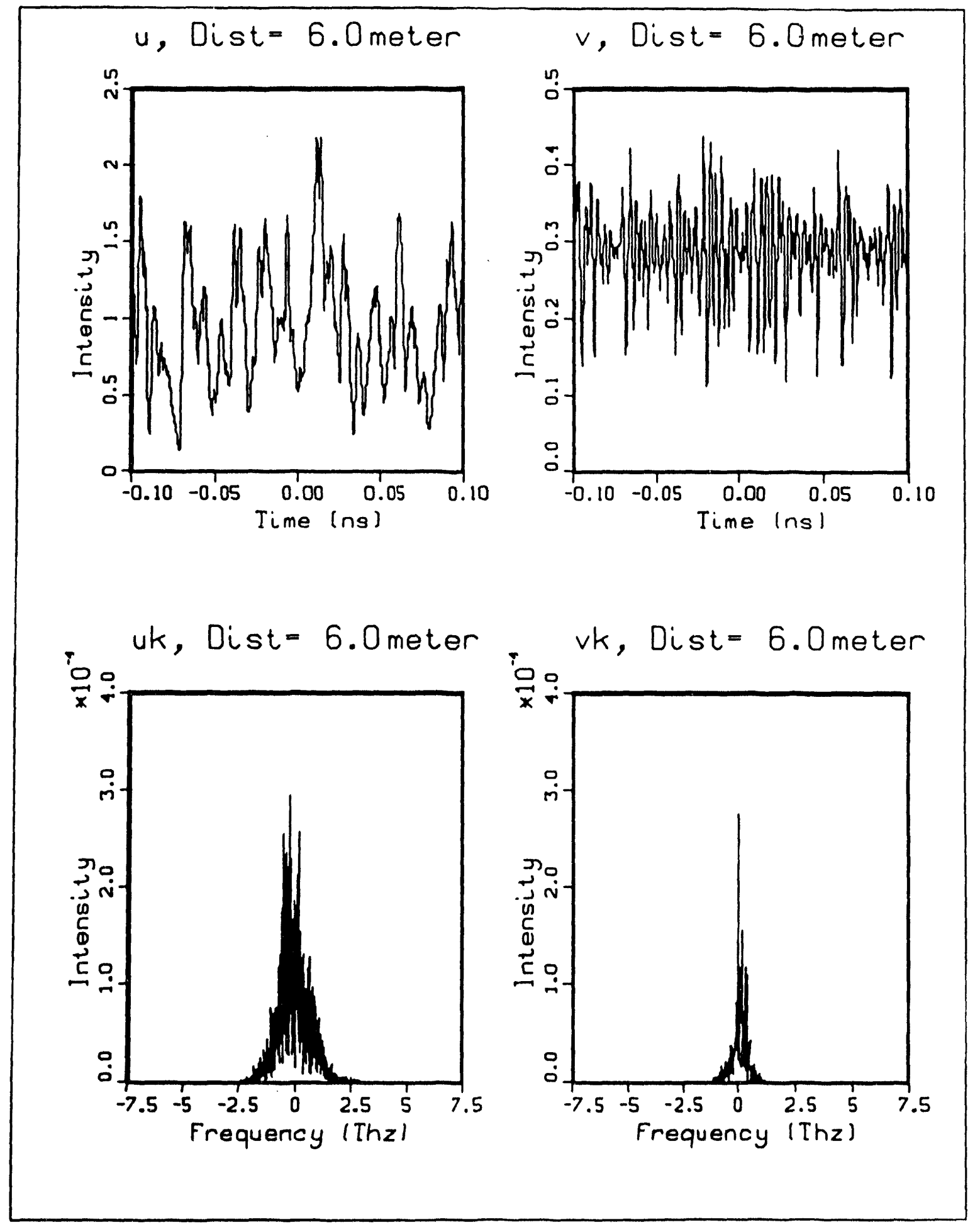




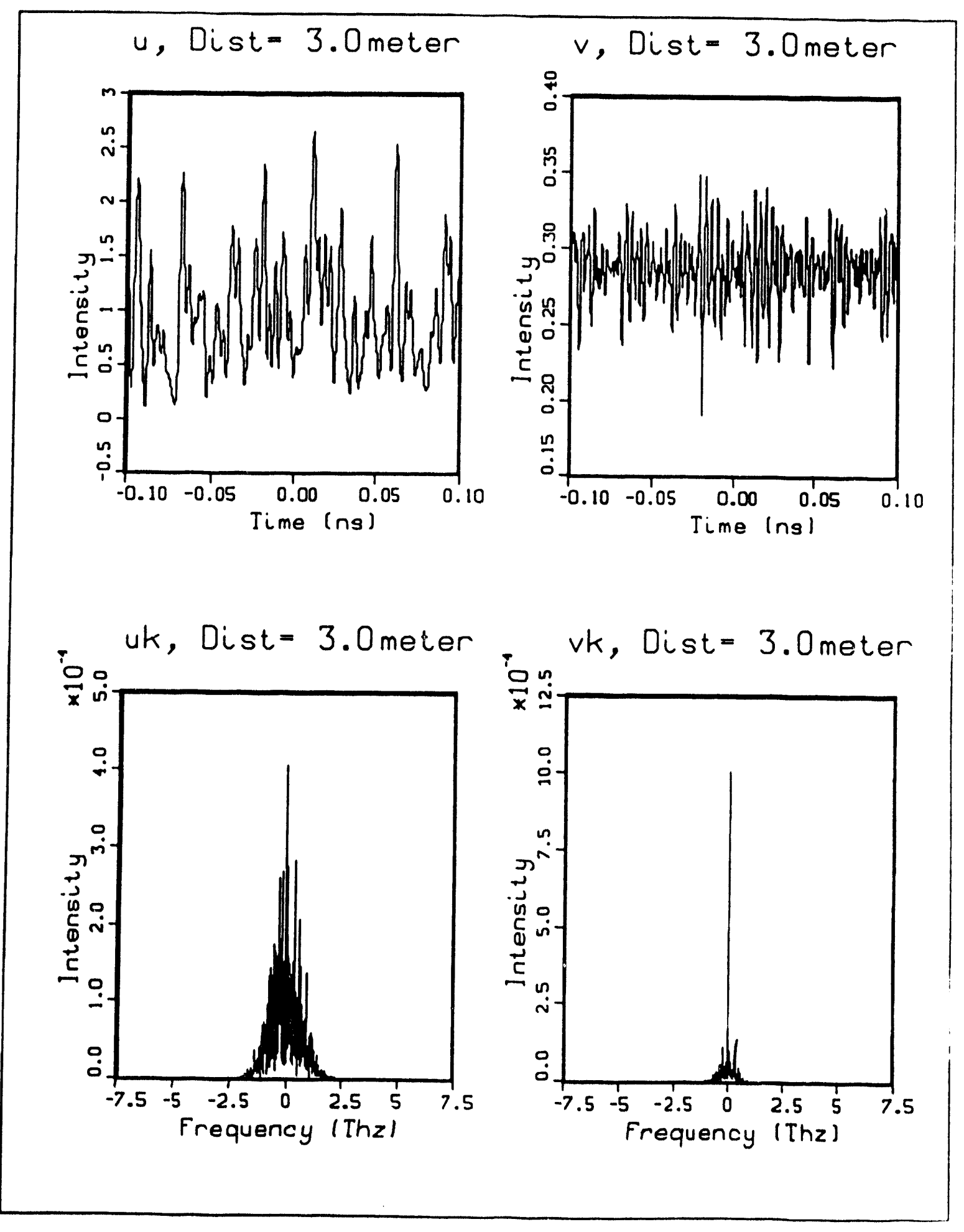



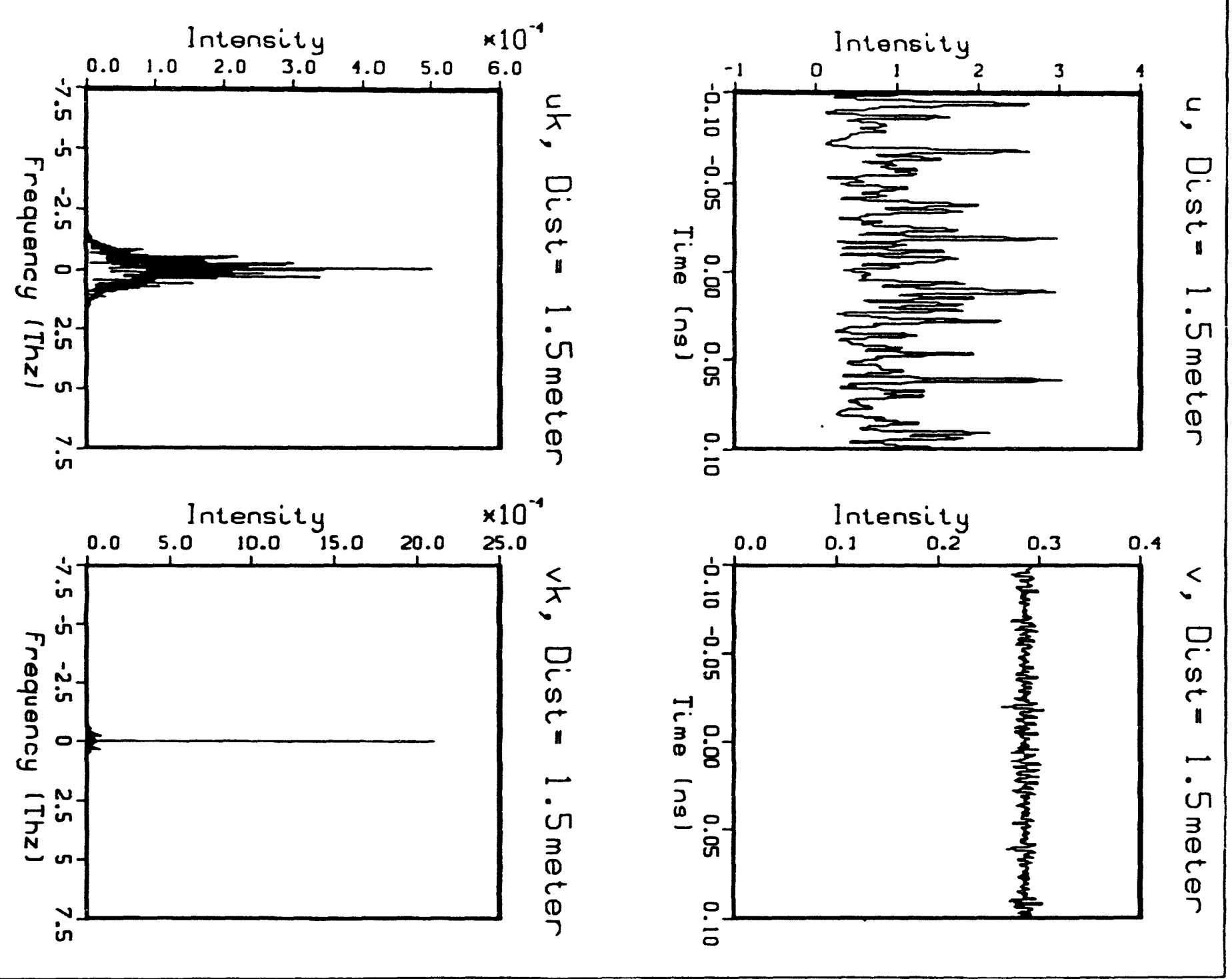


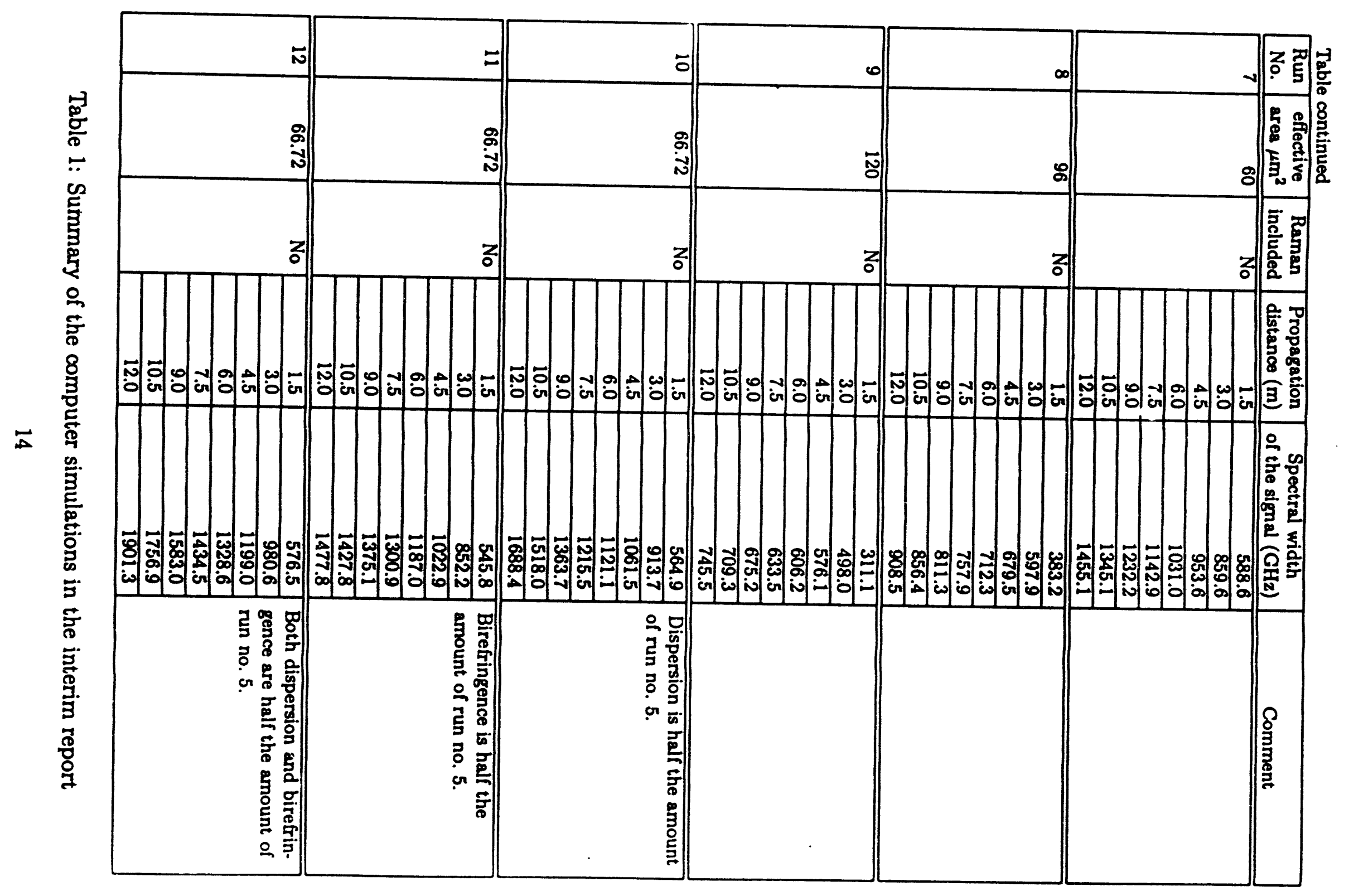




\begin{tabular}{|c|c|c|c|c|c|}
\hline $\begin{array}{l}\text { Run } \\
\text { No. }\end{array}$ & $\begin{array}{c}D(p \sec / \mathrm{nm}-\mathrm{km}) / \\
\Delta n\left(\times 10^{-6}\right)\end{array}$ & Raman & $\begin{array}{l}\text { Propagation } \\
\text { distance }(m)\end{array}$ & $\begin{array}{c}\text { Spectral width (GHz)/ } \\
\text { var/avg }\end{array}$ & Comment \\
\hline \multirow[t]{6}{*}{$\overline{1}$} & \multirow[t]{6}{*}{$-5 / 5$} & \multirow[t]{6}{*}{$\overline{\text { No }}$} & $\overline{\overline{2.0}}$ & $708.4 / 0.0180$ & \\
\hline & & & 4.0 & $1300.4 / 0.0675$ & $\approx 50 A$, smoothest \\
\hline & & & 6.0 & $1734.3 / 0.1438$ & \multirow[t]{4}{*}{$>50 A$} \\
\hline & & & 8.0 & $2002.7 / 0.2440$ & \\
\hline & & & 10.0 & $2190.2 / 0.3377$ & \\
\hline & & & 12.0 & $2443.5 / 0.4043$ & \\
\hline \multirow[t]{6}{*}{2} & \multirow[t]{6}{*}{$-5 / 10$} & \multirow[t]{6}{*}{$\overline{\text { No }}$} & $\overline{2.0}$ & $707.4 / 0.0179$ & \\
\hline & & & 4.0 & $1293.9 / 0.0671$ & \\
\hline & & & 6.0 & $1714.8 / 0.1422$ & \multirow[t]{4}{*}{$>50 A$} \\
\hline & & & 8.0 & $1959.4 / 0.2386$ & \\
\hline & & & 10.0 & $2104.5 / 0.3293$ & \\
\hline & & & 12.0 & $2249.5 / 0.4011$ & \\
\hline \multirow[t]{6}{*}{3} & \multirow[t]{6}{*}{$-5 / 20$} & \multirow[t]{6}{*}{ No } & $\overline{2.0}$ & $703.7 / 0.0178$ & \\
\hline & & & 4.0 & $1267.9 / 0.0658$ & \\
\hline & & & 6.0 & $1643.0 / 0.1352$ & \multirow{4}{*}{$>50 A$} \\
\hline & & & 8.0 & $1834.3 / 0.2182$ & \\
\hline & & & 10.0 & $1925.2 / 0.3022$ & \\
\hline & & & 12.0 & $1986.7 / 0.3712$ & \\
\hline \multirow[t]{6}{*}{4} & \multirow[t]{6}{*}{$-5 / 40$} & \multirow[t]{6}{*}{ No } & 2.0 & $688.7 / 0.0175$ & \\
\hline & & & 4.0 & $1172.3 / 0.0607$ & \\
\hline & & & 6.0 & $1414.9 / 0.1141$ & \multirow[t]{4}{*}{$>50 A$} \\
\hline & & & 8.0 & $1501.3 / 0.1670$ & \\
\hline & & & 10.0 & $1539.8 / 0.2145$ & \\
\hline & & & 12.0 & $1642.1 / 0.2563$ & \\
\hline \multirow[t]{6}{*}{$\overline{5}$} & \multirow[t]{6}{*}{$-5 / 80$} & \multirow[t]{6}{*}{ No } & 2.0 & $632.5 / 0.0160$ & \\
\hline & & & 4.0 & $889.3 / 0.0457$ & \\
\hline & & & 6.0 & $904.9 / 0.0699$ & \\
\hline & & & 8.0 & $889.4 / 0.0880$ & \\
\hline & & & 10.0 & $890.8 / 0.1040$ & \\
\hline & & & 12.0 & $881.5 / 0.1173$ & \\
\hline
\end{tabular}




\begin{tabular}{|c|c|c|c|c|c|}
\hline $\begin{array}{l}\text { Run } \\
\text { No. }\end{array}$ & $\begin{array}{c}D(\mathrm{psec} / \mathrm{nm}-\mathrm{km}) / \\
\Delta n\left(\times 10^{-6}\right)\end{array}$ & Raman & $\begin{array}{l}\text { Propagation } \\
\text { distance }(m)\end{array}$ & $\begin{array}{c}\text { Spectral width (GHz)/ } \\
\text { var/avg }\end{array}$ & Comment \\
\hline \multirow[t]{6}{*}{6} & \multirow[t]{6}{*}{$-10 / 5$} & \multirow[t]{6}{*}{10} & 2.0 & $687.0 / 0.0350$ & \\
\hline & & & 4.0 & $1183.4 / 0.1284$ & \\
\hline & & & 6.0 & $1462.4 / 0.2653$ & \multirow{4}{*}{$>50 A$} \\
\hline & & & 8.0 & $1665.6 / 0.3783$ & \\
\hline & & & 10.0 & $1948.0 / 0.4418$ & \\
\hline & & & 12.0 & $2150.1 / 0.4764$ & \\
\hline \multirow[t]{6}{*}{$\overline{7}$} & \multirow[t]{6}{*}{$-10 / 10$} & \multirow[t]{6}{*}{ No } & 2.0 & $686.1 / 0.0350$ & \\
\hline & & & 4.0 & $1178.0 / 0.1278$ & \\
\hline & & & 6.0 & $1441.6 / 0.2622$ & \multirow[t]{4}{*}{$>50 A$} \\
\hline & & & 8.0 & $1634.7 / 0.3735$ & \\
\hline & & & 10.0 & $1819.8 / 0.4395$ & \\
\hline & & & 12.0 & $1987.0 / 0.4755$ & \\
\hline \multirow[t]{6}{*}{8} & \multirow[t]{6}{*}{$-10 / 20$} & \multirow[t]{6}{*}{$\overline{\text { No }}$} & 2.0 & $682.5 / 0.0348$ & \\
\hline & & & 4.0 & $1154.9 / 0.1251$ & \\
\hline & & & 6.0 & $1 3 8 1 . 0 \longdiv { 0 . 2 4 9 3 }$ & \multirow[t]{4}{*}{$>50 A$} \\
\hline & & & 8.0 & $1487.0 / 0.3611$ & \\
\hline & & & 10.0 & $1577.2 / 0.4464$ & \\
\hline & & & 12.0 & $1672.2 / 0.4964$ & \\
\hline \multirow[t]{6}{*}{$\overline{\overline{9}}$} & \multirow[t]{6}{*}{$-10 / 40$} & \multirow[t]{6}{*}{$\overline{\text { No }}$} & $\overline{2.0}$ & $668.3 / 0.0341$ & \multirow{4}{*}{ 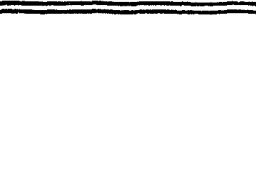 } \\
\hline & & & 4.0 & $1072.6 / 0.1152$ & \\
\hline & & & 6.0 & $1220.7 / 0.2121$ & \\
\hline & & & 8.0 & $1268.7 / 0.3006$ & \\
\hline & & & 10.0 & $1323.2 / 0.3654$ & \multirow[t]{2}{*}{$>50 A$} \\
\hline & & & 12.0 & $1424.1 / 0.4062$ & \\
\hline \multirow[t]{6}{*}{$\overline{10}$} & \multirow[t]{6}{*}{$-10 / 80$} & \multirow[t]{6}{*}{$\overline{\text { No }}$} & $\overline{\overline{2.0}}$ & $\overline{615.8 / 0.0314}$ & \\
\hline & & & 4.0 & $837.0 / 0.0881$ & \\
\hline & & & 6.0 & $859.4 / 0.1354$ & \\
\hline & & & 8.0 & $884.9 / 0.1711$ & \\
\hline & & & 10.0 & $920.9 / 0.1965$ & \\
\hline & & & 12.0 & $927.3 / 0.2133$ & \\
\hline
\end{tabular}




\begin{tabular}{|c|c|c|c|c|c|}
\hline $\begin{array}{l}\text { Run } \\
\text { No. }\end{array}$ & $\begin{array}{c}D(\mathrm{psec} / \mathrm{nm}-\mathrm{km}) / \\
\Delta n\left(\times 10^{-6}\right)\end{array}$ & Raman & $\begin{array}{l}\text { Propagation } \\
\text { distance }(m) \\
\end{array}$ & $\begin{array}{c}\text { Spectral width (GHz)/ } \\
\text { var/avg }\end{array}$ & Comment \\
\hline \multirow[t]{6}{*}{11} & \multirow[t]{6}{*}{$-20 / 5$} & \multirow[t]{6}{*}{ No } & $\overline{2.0}$ & $650.0 / 0.0672$ & \\
\hline & & & $\overline{4.0}$ & $1016.7 / 0.2355$ & \\
\hline & & & 6.0 & $1222.3 / 0.3925$ & \\
\hline & & & 8.0 & $1491.0 / 0.4654$ & \multirow[t]{3}{*}{$>50 A$} \\
\hline & & & 10.0 & $1712.8 / 0.5050$ & \\
\hline & & & 12.0 & $1838.8 / 0.5375$ & \\
\hline \multirow[t]{6}{*}{$\overline{12}$} & \multirow[t]{6}{*}{$-20 / 10$} & \multirow[t]{6}{*}{$\overline{\text { No }}$} & $\overline{2.0}$ & $649.5 / 0.0671$ & \\
\hline & & & 4.0 & $1010.4 / 0.2345$ & \\
\hline & & & 6.0 & $1222.3 / 0.3871$ & \\
\hline & & & 8.0 & $1474.3 / 0.4604$ & \multirow[t]{3}{*}{$>50 A$} \\
\hline & & & 10.0 & $1663.8 / 0.4907$ & \\
\hline & & & 12.0 & $1823.1 / 0.5169$ & \\
\hline \multirow[t]{6}{*}{13} & \multirow[t]{6}{*}{$-20 / 20$} & \multirow[t]{6}{*}{ No } & $\overline{2.0}$ & $646.2 / 0.0688$ & \\
\hline & & & 4.0 & $988.7 / 0.2295$ & \\
\hline & & & 6.0 & $1160.1 / 0.3751$ & \\
\hline & & & 8.0 & $1314.6 / 0.4459$ & \multirow[t]{3}{*}{$>50 A$} \\
\hline & & & 10.0 & $1428.0 / 0.4895$ & \\
\hline & & & 12.0 & $1442.1 / 0.5293$ & \\
\hline \multirow[t]{6}{*}{$\overline{14}$} & \multirow[t]{6}{*}{$-20 / 40$} & \multirow[t]{6}{*}{$\overline{\text { No }}$} & 2.0 & $633.3 / 0.0655$ & \\
\hline & & & 4.0 & $922.3 / 0.2115$ & \\
\hline & & & 6.0 & $1004.9 / 0.3517$ & \\
\hline & & & 8.0 & $1087.4 / 0.4375$ & \\
\hline & & & 10.0 & $1227.5 / 0.4669$ & \\
\hline & & & 12.0 & $1332.2 / 0.5011$ & $>50 A$ \\
\hline \multirow[t]{6}{*}{15} & \multirow[t]{6}{*}{$.20 / 80$} & \multirow[t]{6}{*}{ No } & 2.0 & $585.8 / 0.0604$ & \\
\hline & & & 4.0 & $752.3 / 0.1647$ & \\
\hline & & & 6.0 & $793.9 / 0.2481$ & \\
\hline & & & 8.0 & $872.7 / 0.3050$ & \\
\hline & & & 10.0 & $960.5 / 0.3385$ & \\
\hline & & & 12.0 & $1009.2 / 0.3634$ & \\
\hline
\end{tabular}




\begin{tabular}{|c|c|c|c|c|c|}
\hline $\begin{array}{l}\text { Run } \\
\text { No. }\end{array}$ & $\begin{array}{c}D(\mathrm{psec} / \mathrm{nm}-\mathrm{km}) / \\
\Delta n\left(\times 10^{-6}\right) \\
\end{array}$ & Raman & $\begin{array}{l}\text { Propagation } \\
\text { distance }(m)\end{array}$ & $\begin{array}{c}\text { Spectral width (GHz)/ } \\
\text { var/avg } \\
\end{array}$ & Comment \\
\hline \multirow[t]{6}{*}{16} & \multirow[t]{6}{*}{$-40 / 5$} & \multirow[t]{6}{*}{$\overline{\text { No }}$} & 2.0 & $592.1 / 0.1257$ & \\
\hline & & & 4.0 & $848.4 / 0.3609$ & \\
\hline & & & 6.0 & $1078.1 / 0.4815$ & \\
\hline & & & 8.0 & $1290.6 / 0.5239$ & \\
\hline & & & 10.0 & $1382.7 / 0.5744$ & \multirow[t]{2}{*}{$>50 A$} \\
\hline & & & 12.0 & $1432.1 / 0.5954$ & \\
\hline \multirow[t]{6}{*}{17} & \multirow[t]{6}{*}{$-40 / 10$} & \multirow[t]{6}{*}{ No } & $\overline{\overline{2.0}}$ & $\overline{591.3 / 0.1256}$ & \\
\hline & & & 4.0 & $846.8 / 0.3586$ & \\
\hline & & & 6.0 & $1095.7 / 0.4704$ & \\
\hline & & & 8.0 & $1307.9 / 0.5216$ & \multirow[t]{3}{*}{$>50 A$} \\
\hline & & & 10.0 & $1385.4 / 0.5637$ & \\
\hline & & & 12.0 & $1387.5 / 0.5843$ & \\
\hline \multirow[t]{6}{*}{18} & \multirow[t]{6}{*}{$-40 / 20$} & \multirow[t]{6}{*}{$\overline{\text { No }}$} & $\overline{2.0}$ & $588.3 / 0.1251$ & \\
\hline & & & 4.0 & $35.1 / 0.3509$ & \\
\hline & & & 6.0 & $1062.1 / 0.4562$ & \\
\hline & & & 8.0 & $1251.9 / 0.5017$ & \\
\hline & & & 10.0 & $1332.4 / 0.5385$ & \multirow[t]{2}{*}{$>50 \AA$} \\
\hline & & & 12.0 & $1357.8 / 0.5534$ & \\
\hline \multirow[t]{6}{*}{19} & \multirow[t]{6}{*}{$-40 / 40$} & \multirow[t]{6}{*}{$\overline{\text { No }}$} & $\overline{2.0}$ & $\overline{577.1 / 0.1226}$ & \\
\hline & & & 4.0 & $775.3 / 0.3300$ & \\
\hline & & & 6.0 & $906.3 / 0.4343$ & \\
\hline & & & 8.0 & $977.1 / 0.5000$ & \\
\hline & & & 10.0 & $1018.9 / 0.5630$ & \\
\hline & & & 12.0 & $1050.8 / 0.5941$ & \\
\hline \multirow[t]{6}{*}{20} & \multirow[t]{6}{*}{$-40 / 80$} & \multirow[t]{6}{*}{ No } & $\overline{2.0}$ & $\overline{536.5 / 0.1134}$ & \\
\hline & & & 4.0 & $649.4 / 0.2813$ & \\
\hline & & & 6.0 & $743.6 / 0.3792$ & \\
\hline & & & 8.0 . & $855.6 / 0.4344$ & \\
\hline & & & 10.0 & $913.6 / 0.4830$ & \\
\hline & & & 12.0 & $988.3 / 0.5074$ & \\
\hline
\end{tabular}




\begin{tabular}{|c|c|c|c|c|c|}
\hline $\begin{array}{l}\text { Run } \\
\text { No. }\end{array}$ & $\begin{array}{c}D \text { (psec/nm-km)/ } \\
\Delta n\left(\times 10^{-6}\right)\end{array}$ & Raman & $\begin{array}{l}\text { Propagation } \\
\text { distance }(m)\end{array}$ & $\begin{array}{c}\text { Spectral width }(\mathrm{GHz}) / \\
\text { var/avg }\end{array}$ & Comment \\
\hline \multirow[t]{6}{*}{21} & \multirow[t]{6}{*}{$-5 / 20$} & \multirow[t]{6}{*}{$\overline{\overline{Y e s}}$} & $\overline{\overline{2.0}}$ & $\overline{703.8 / 0.0174}$ & \multirow{6}{*}{$\begin{array}{l}\text { Compared with run } \\
\text { no. } 3 \text { in this Table. }\end{array}$} \\
\hline & & & 4.0 & $1268.4 / 0.0603$ & \\
\hline & & & 6.0 & $1642.9 / 0.1195$ & \\
\hline & & & 8.0 & $1833.9 / 0.1870$ & \\
\hline & & & 10.0 & $1924.6 / 0.2537$ & \\
\hline & & & 12.0 & $2000.6 / 0.3088$ & \\
\hline \multirow[t]{6}{*}{22} & \multirow[t]{6}{*}{$-10 / 80$} & \multirow[t]{6}{*}{ Yes } & $\overline{\overline{2.0}}$ & $615.6 / 0.0283$ & \multirow{6}{*}{$\begin{array}{l}\text { Compared with run } \\
\text { no. } 10 \text { in this Table. }\end{array}$} \\
\hline & & & 4.0 & $837.5 / 0.0751$ & \\
\hline & & & 6.0 & $866.2 / 0.1175$ & \\
\hline & & & 8.0 & $909.8 / 0.1574$ & \\
\hline & & & 10.0 & $961.6 / 0.1878$ & \\
\hline & & & 12.0 & $977.4 / 0.2104$ & \\
\hline \multirow[t]{6}{*}{$\overline{23}$} & \multirow[t]{6}{*}{$-20 / 5$} & \multirow[t]{6}{*}{$\overline{Y e s}$} & 2.0 & $650.2 / 0.0673$ & \multirow{6}{*}{$\begin{array}{l}\text { Compared with run } \\
\text { no. } 11 \text { in this Table. }\end{array}$} \\
\hline & & & 4.0 & $1016.5 / 0.2352$ & \\
\hline & & & 6.0 & $1229.6 / 0.3928$ & \\
\hline & & & 8.0 & $1524.4 / 0.4639$ & \\
\hline & & & 10.0 & $1755.9 / 0.5018$ & \\
\hline & & & 12.0 & $1863.0 / 0.5338$ & \\
\hline \multirow[t]{6}{*}{$\overline{\overline{24}}$} & \multirow[t]{6}{*}{$-40 / 40$} & \multirow[t]{6}{*}{$\overline{\text { Yes }}$} & $\overline{2.0}$ & $576.8 / 0.1214$ & \multirow{6}{*}{$\begin{array}{l}\text { Compared with run } \\
\text { no. } 19 \text { in this Table. }\end{array}$} \\
\hline & & & 4.0 & $775.8 / 0.3240$ & \\
\hline & & & 6.0 & $907.5 / 0.4216$ & \\
\hline & & & 8.0 & $979.8 / 0.4846$ & \\
\hline & & & 10.0 & $1026.3 / 0.5435$ & \\
\hline & & & 12.0 & $1056.8 / 0.5780$ & \\
\hline
\end{tabular}

Table 2: A summary of computer simulation of different birefringence and dispersion 



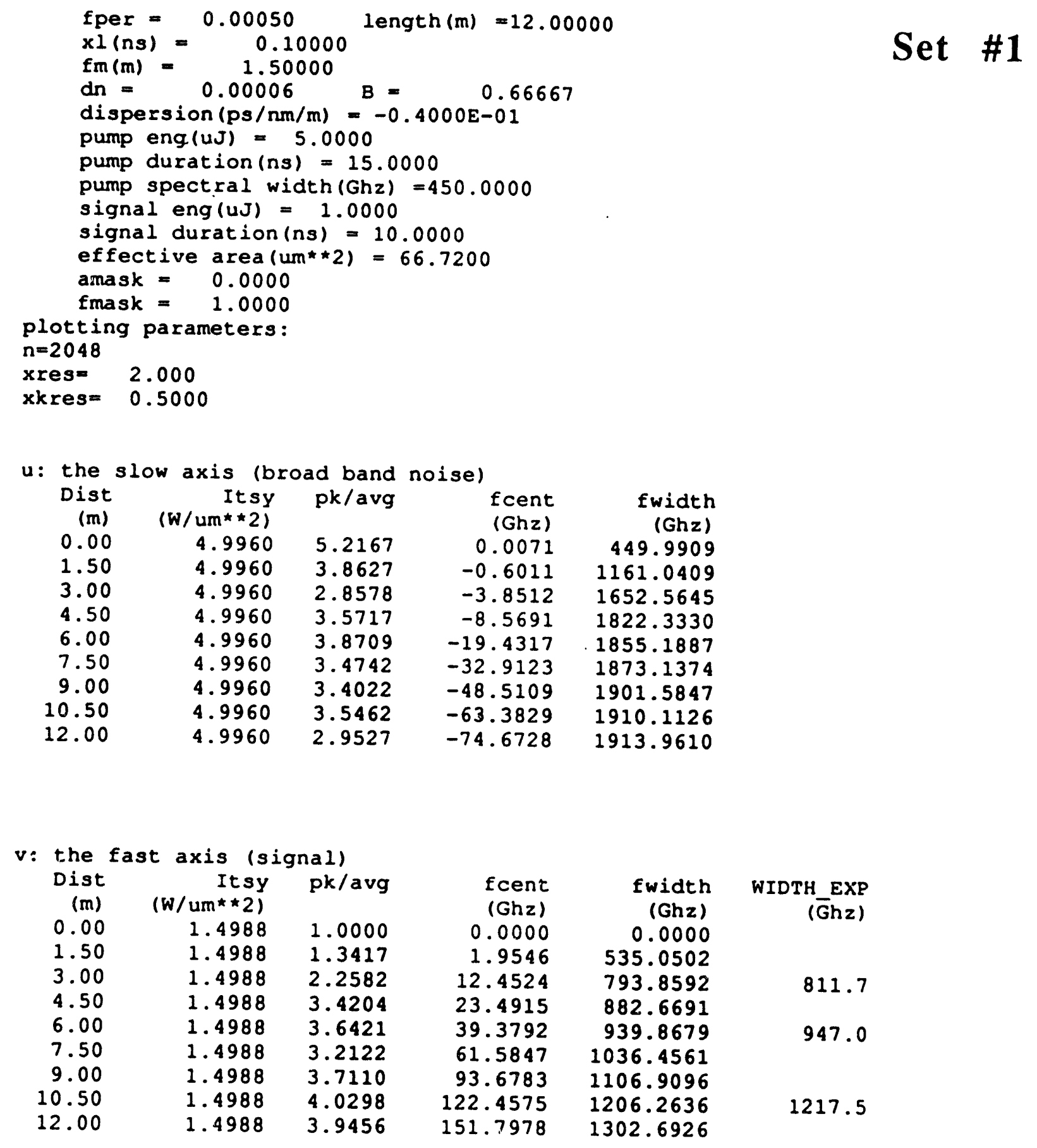




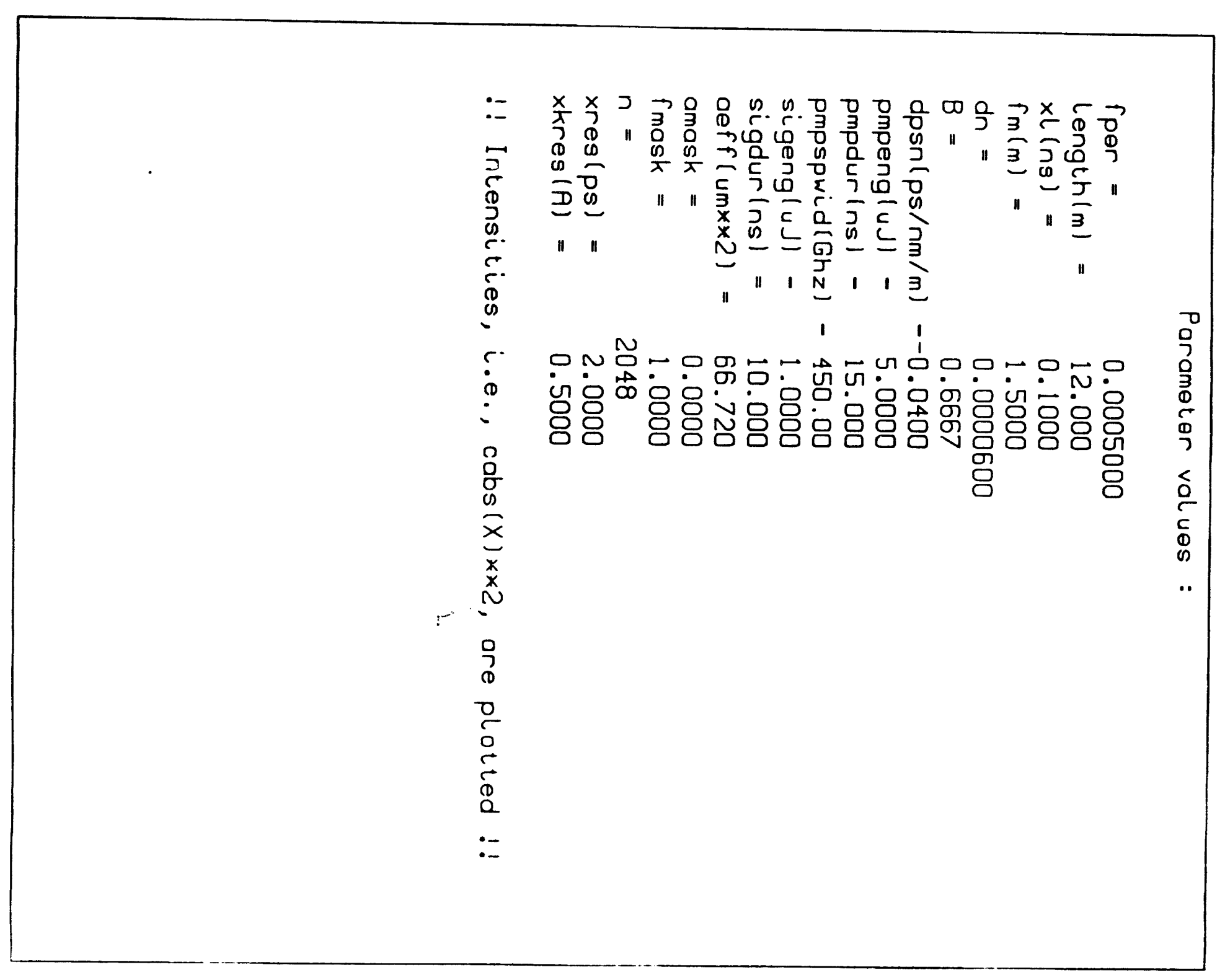




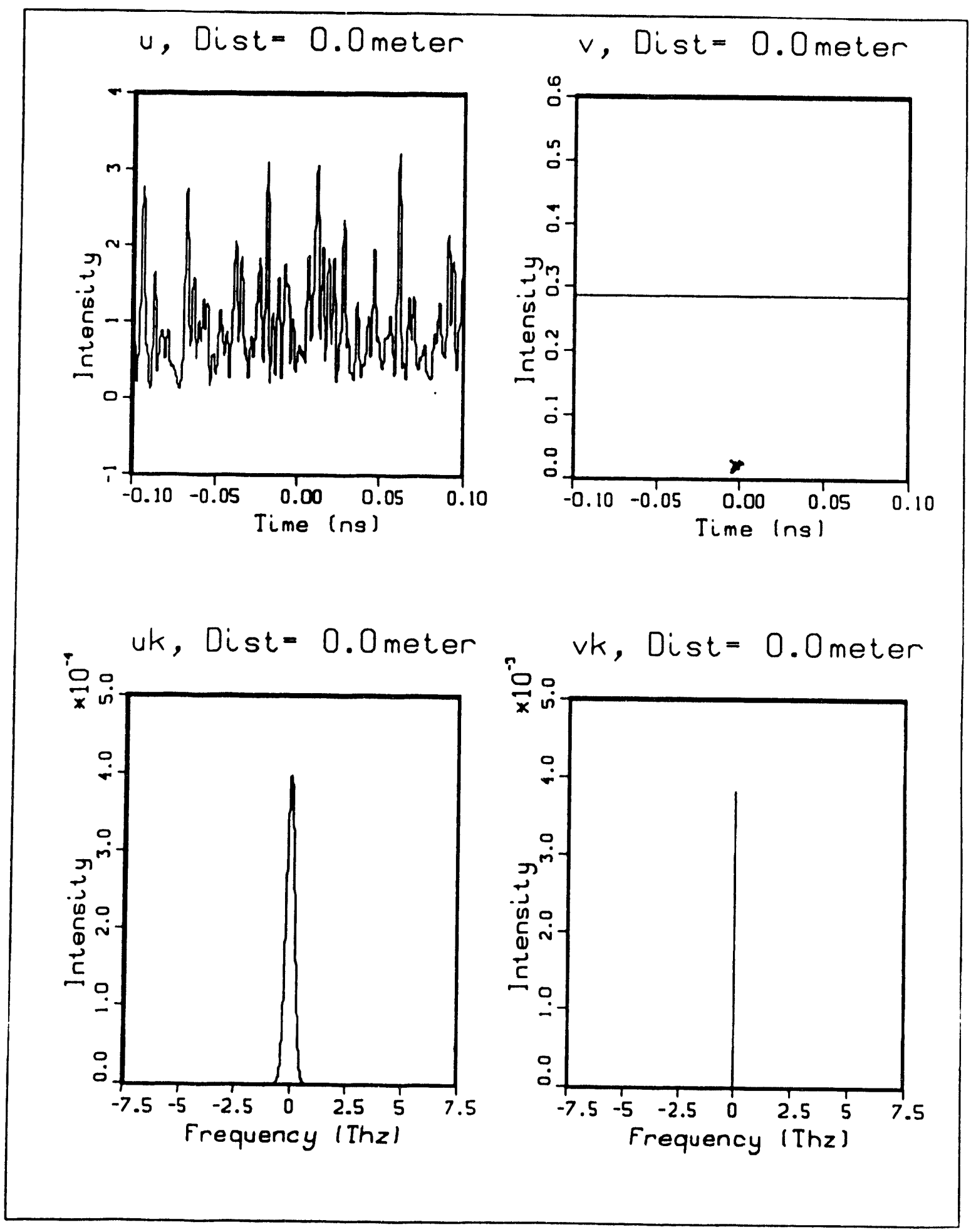




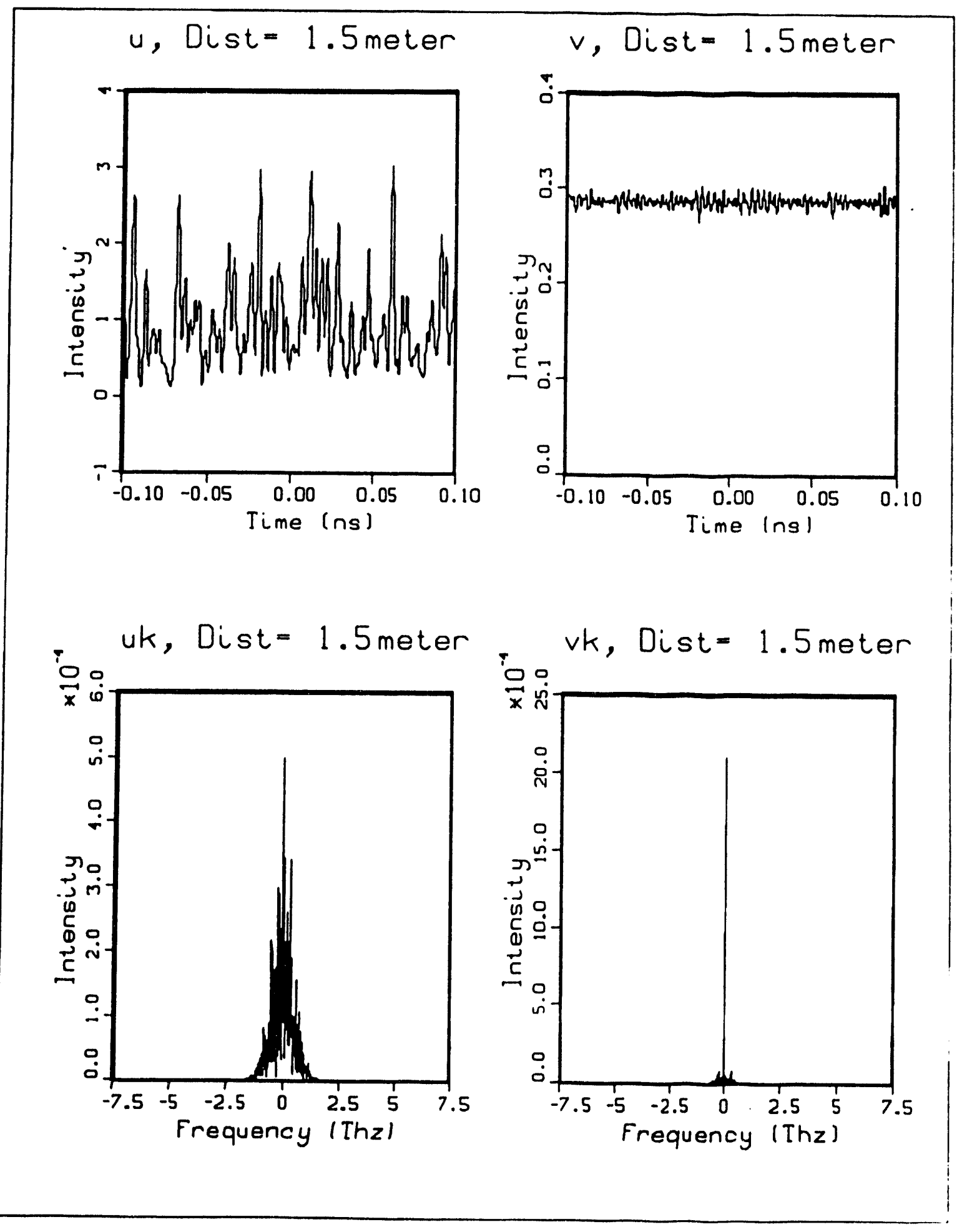




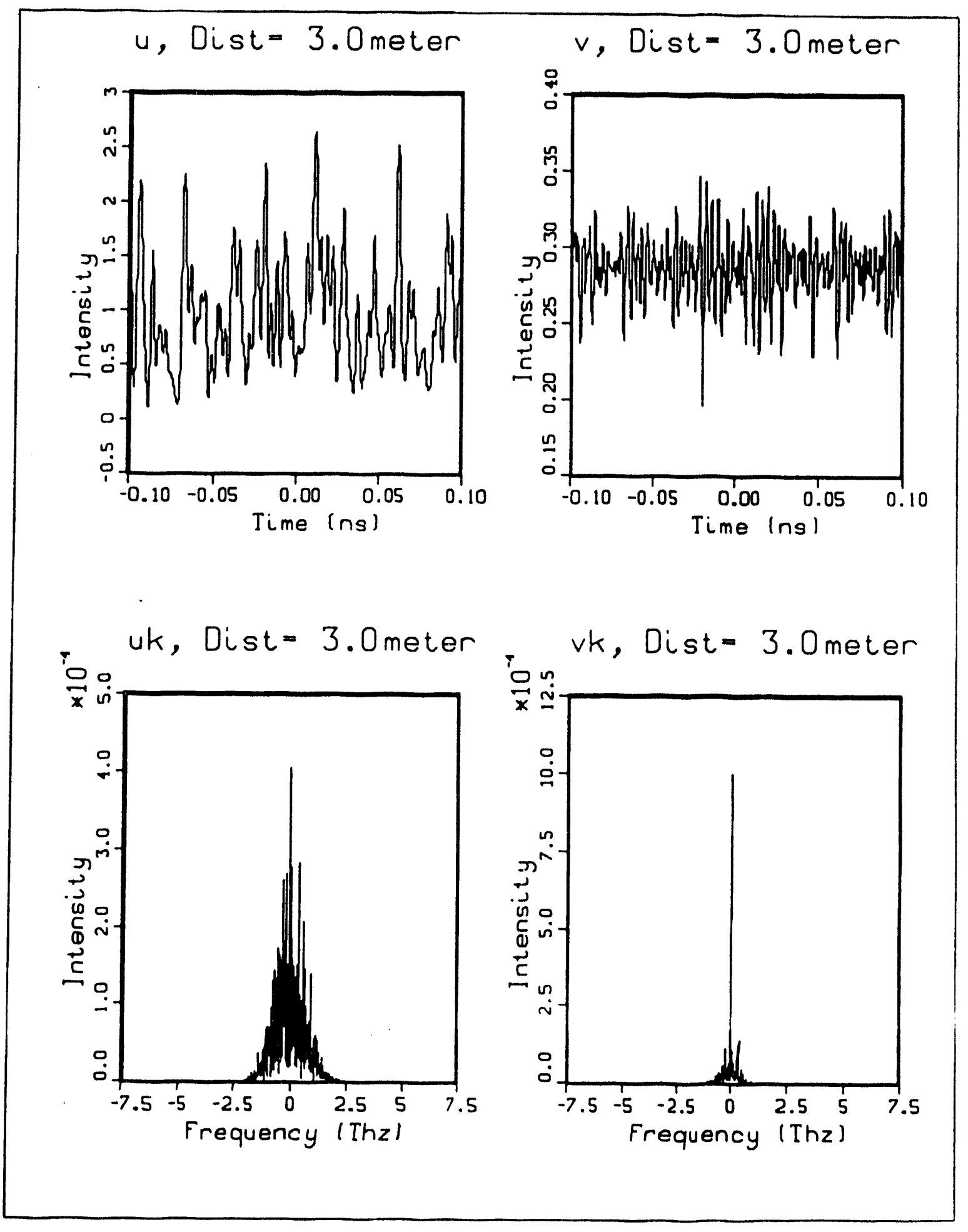




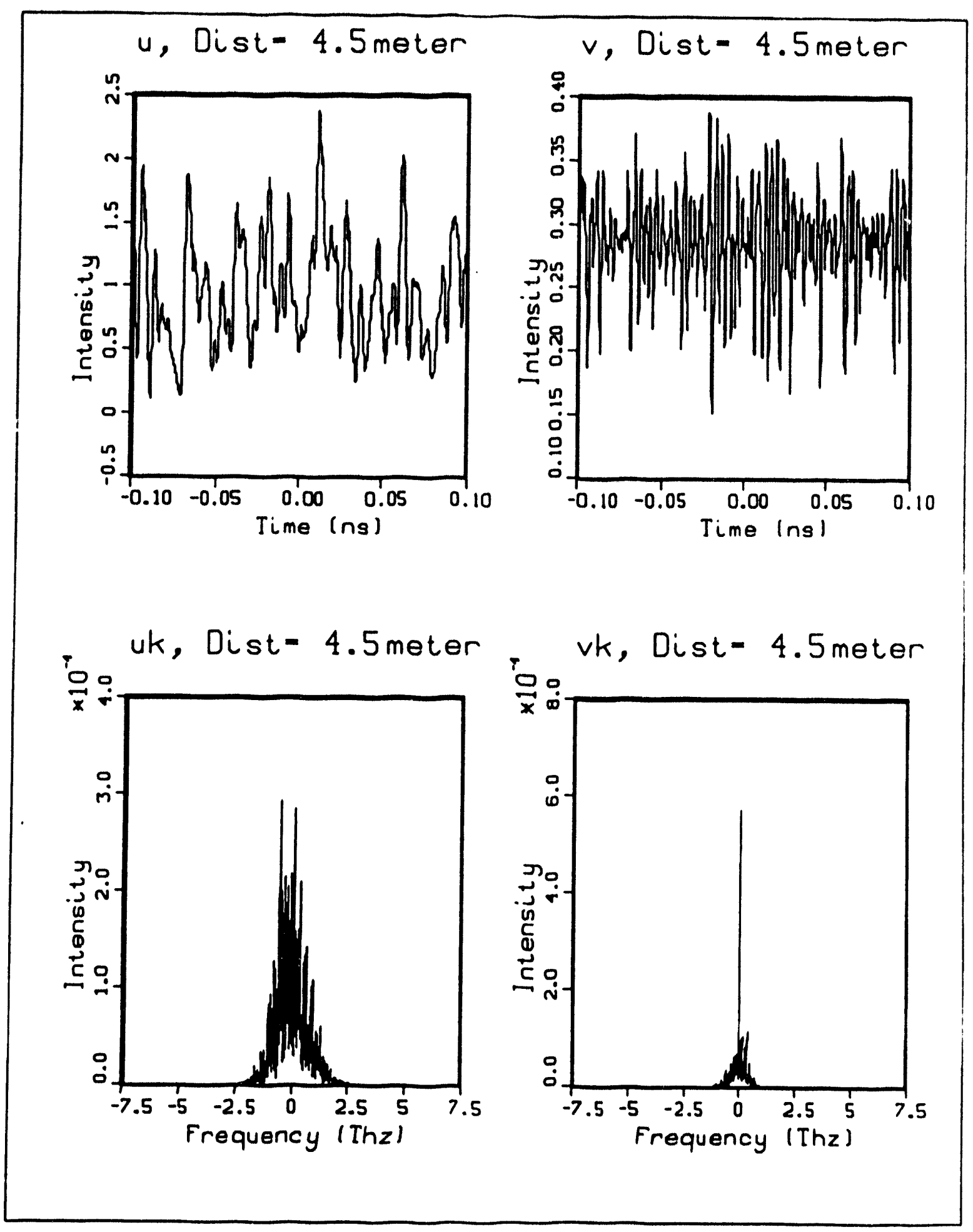




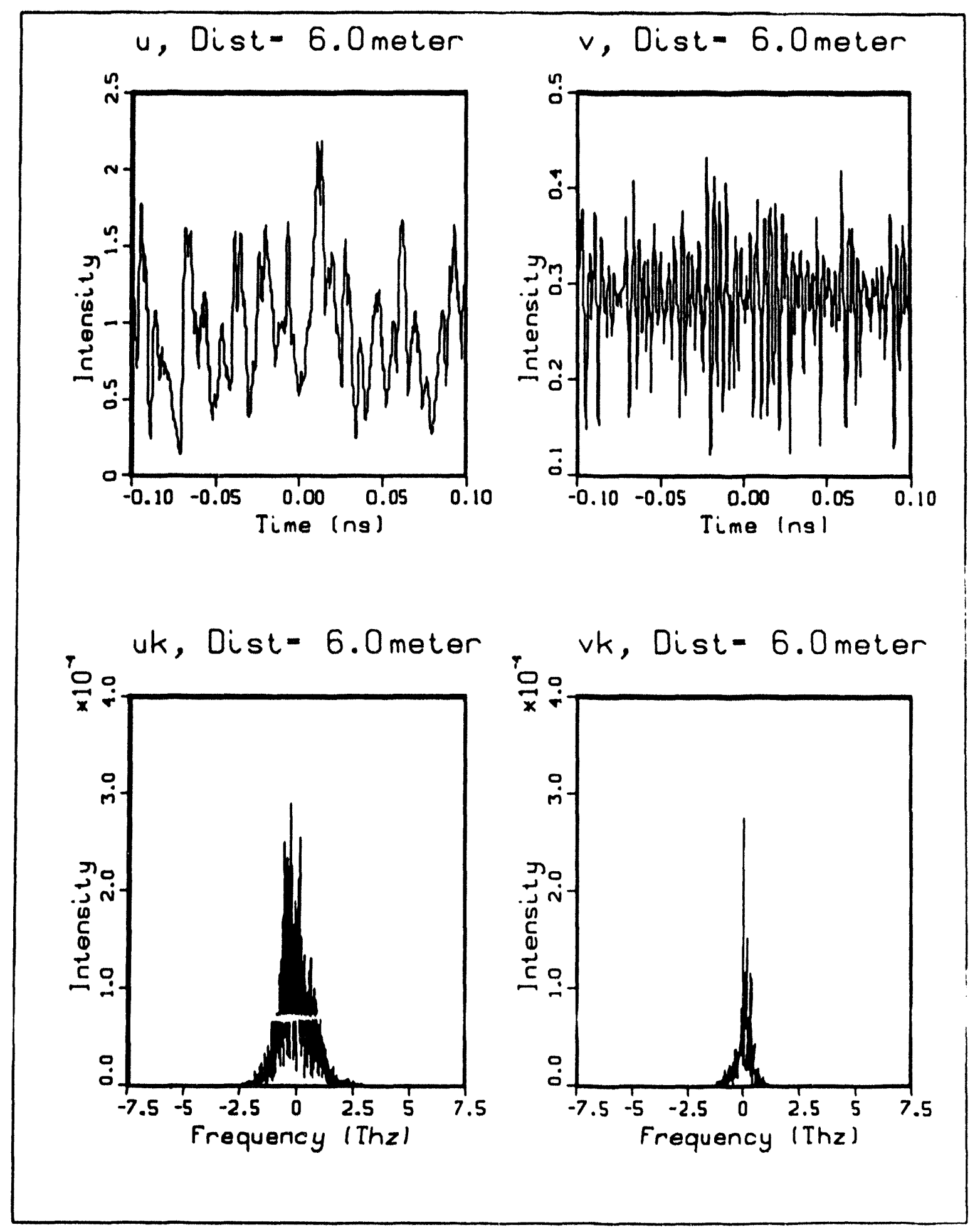



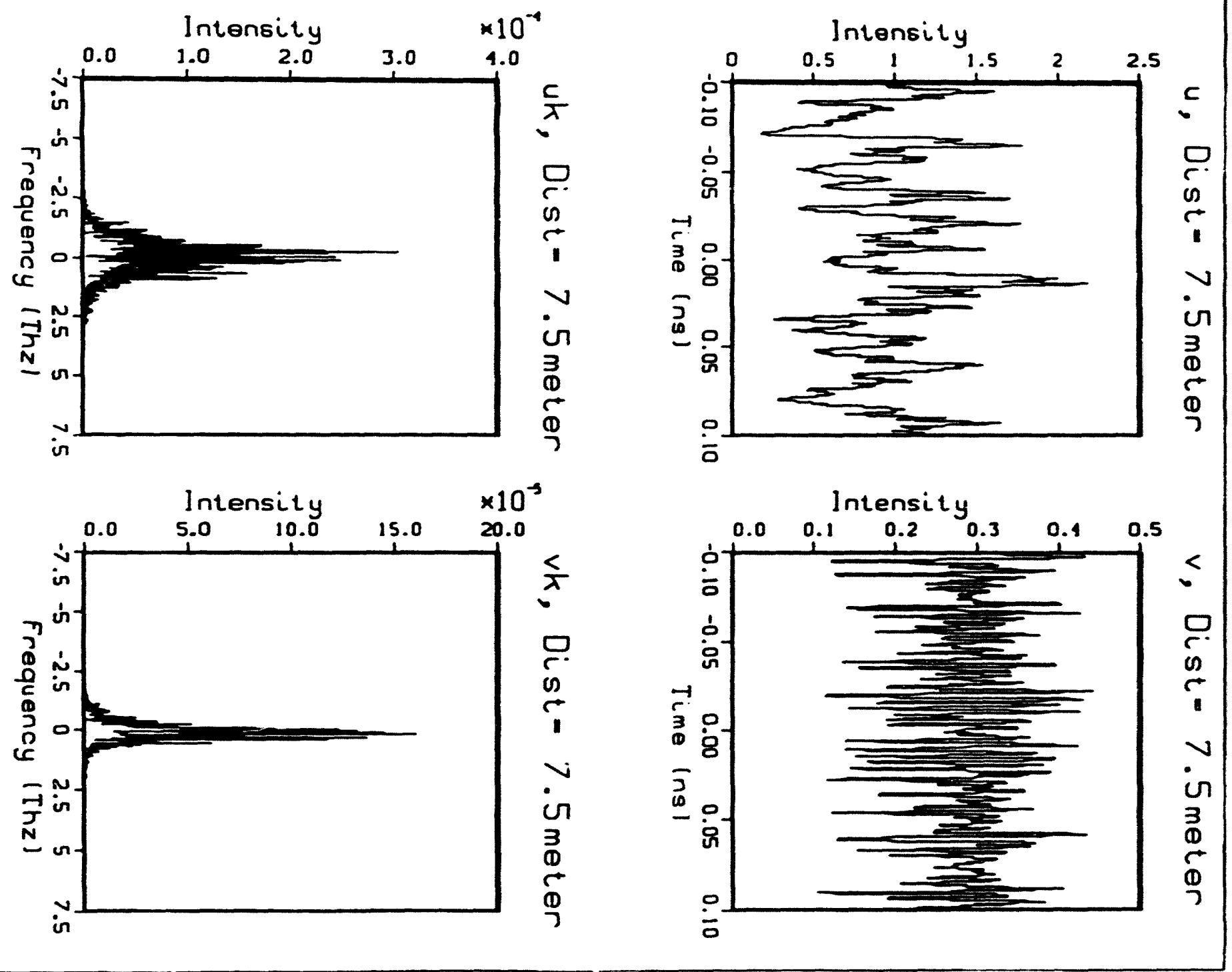

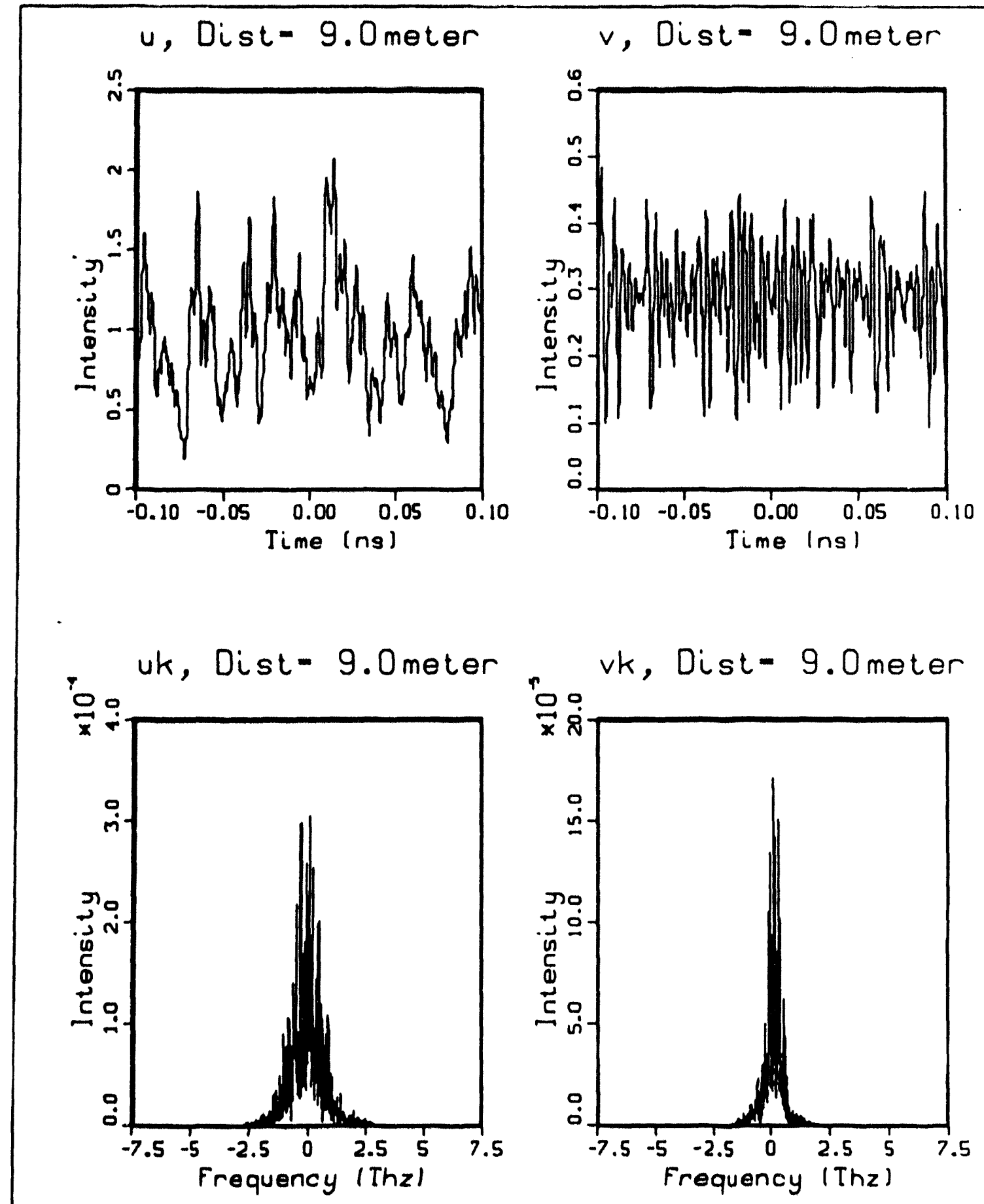


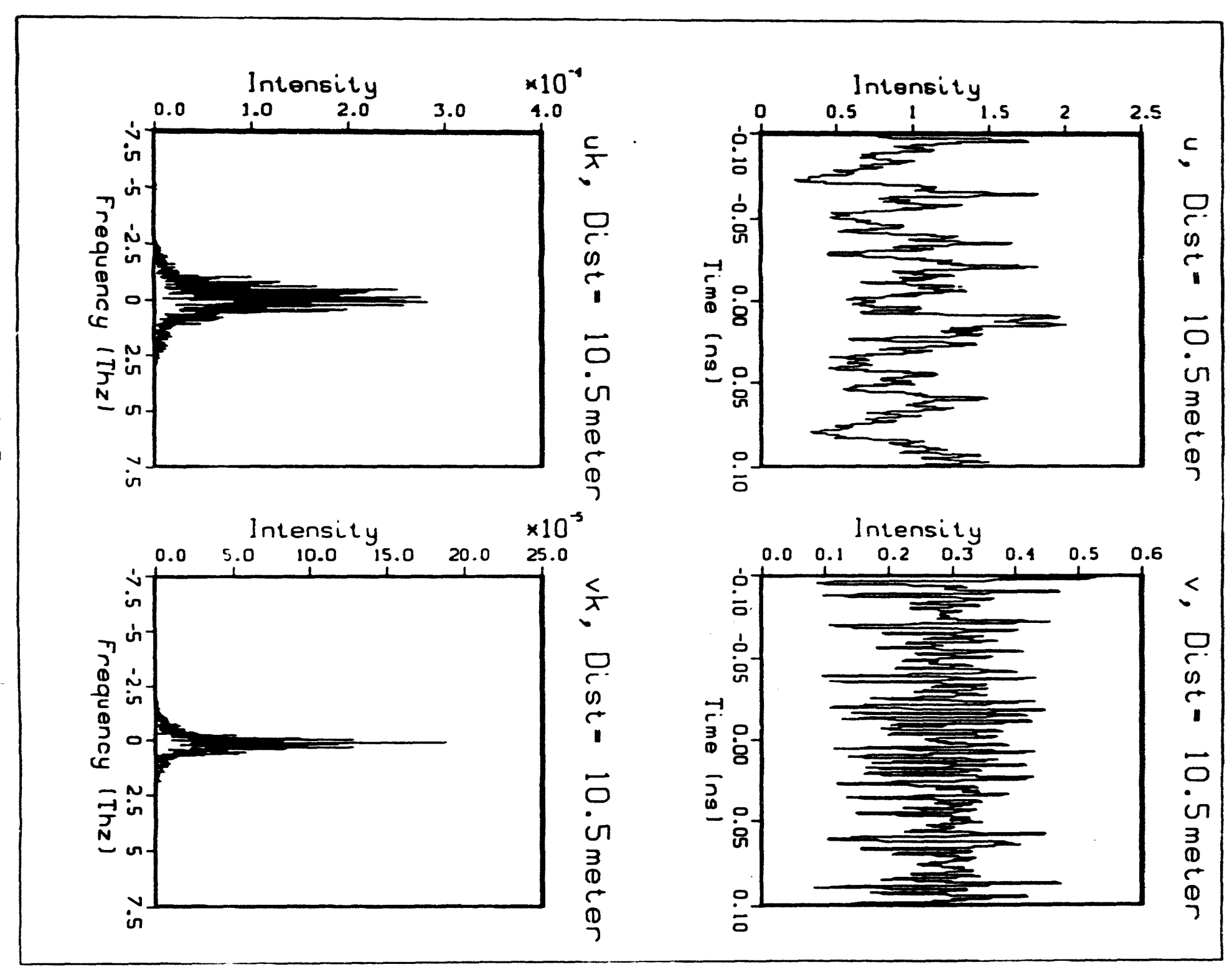




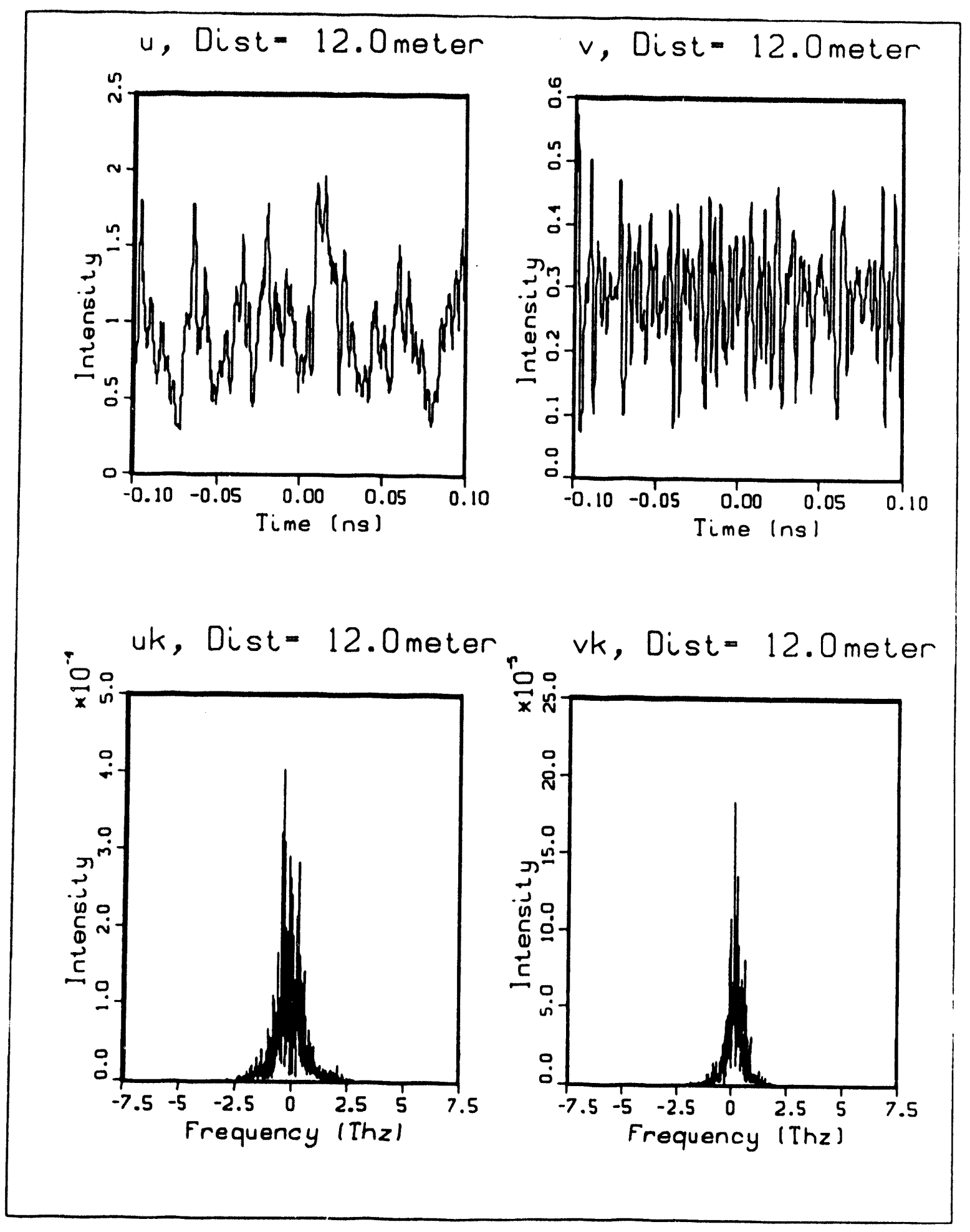




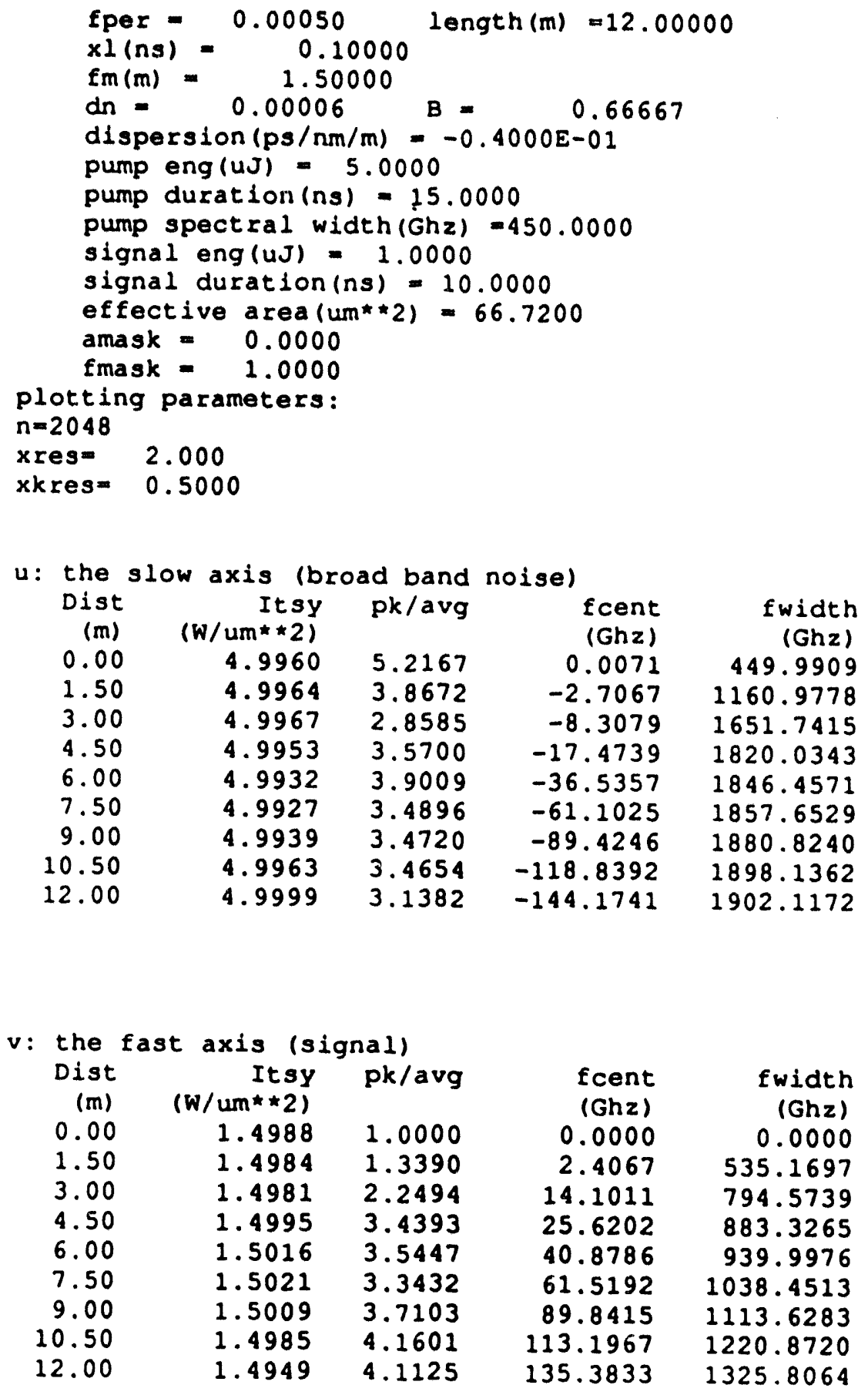




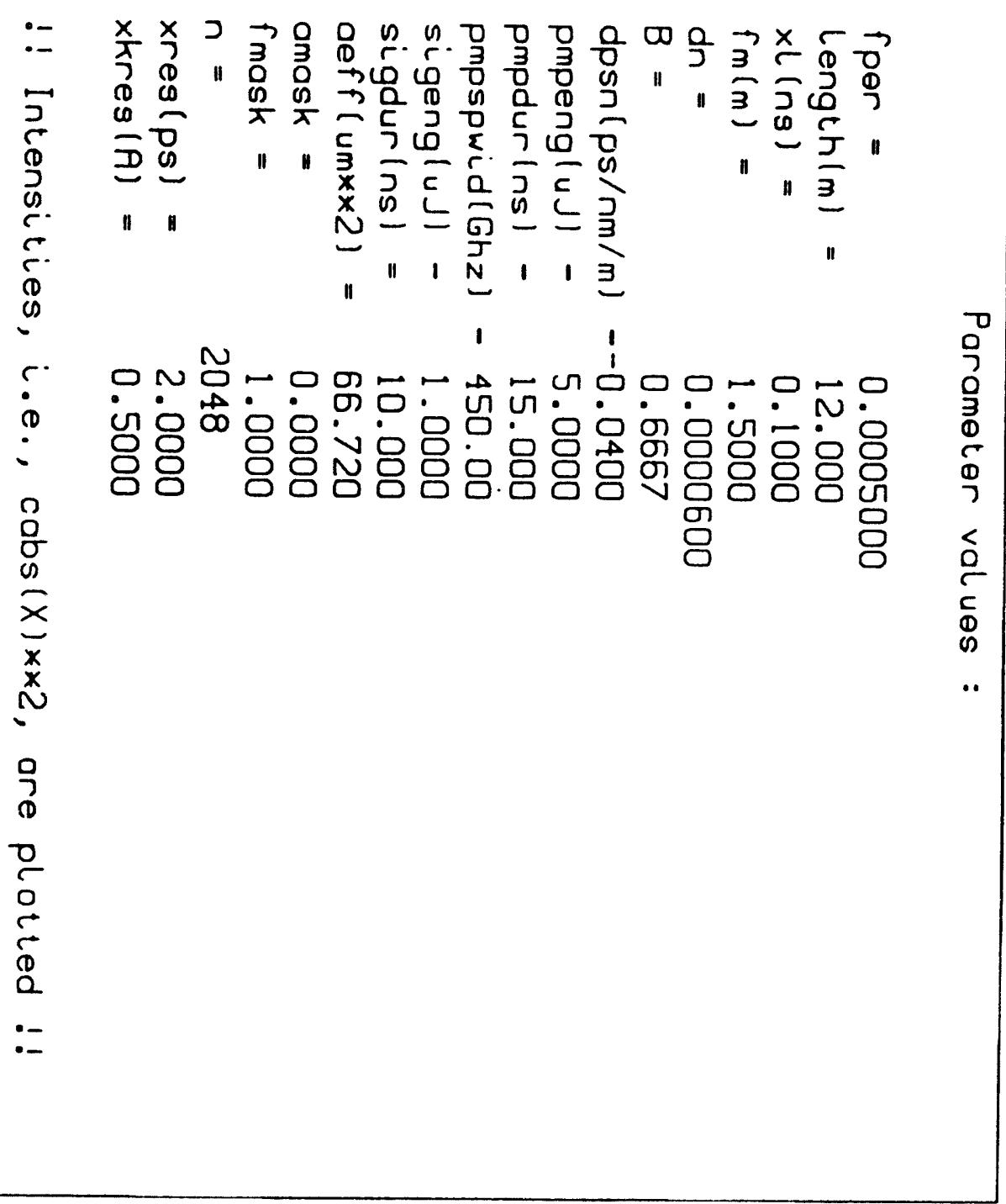



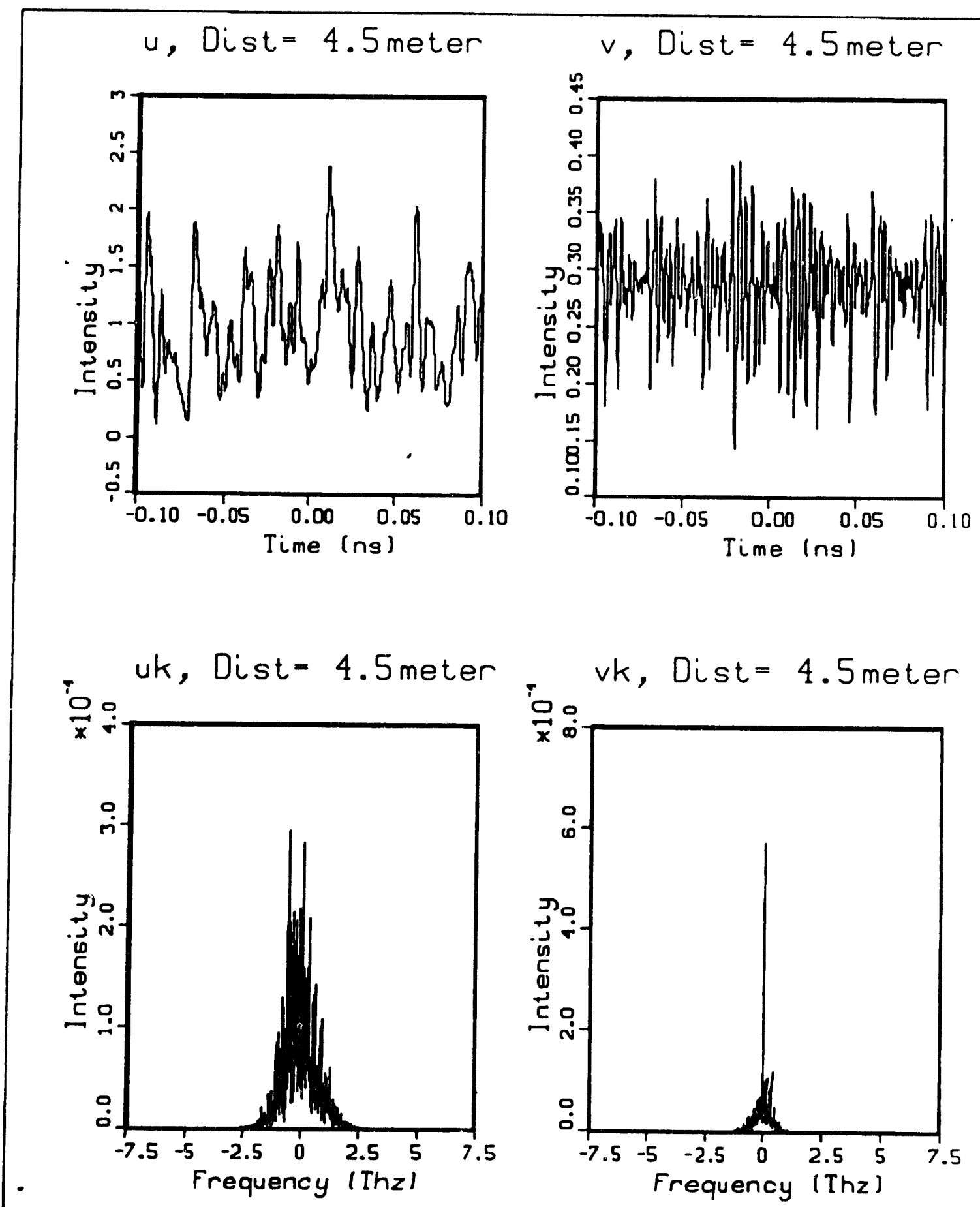


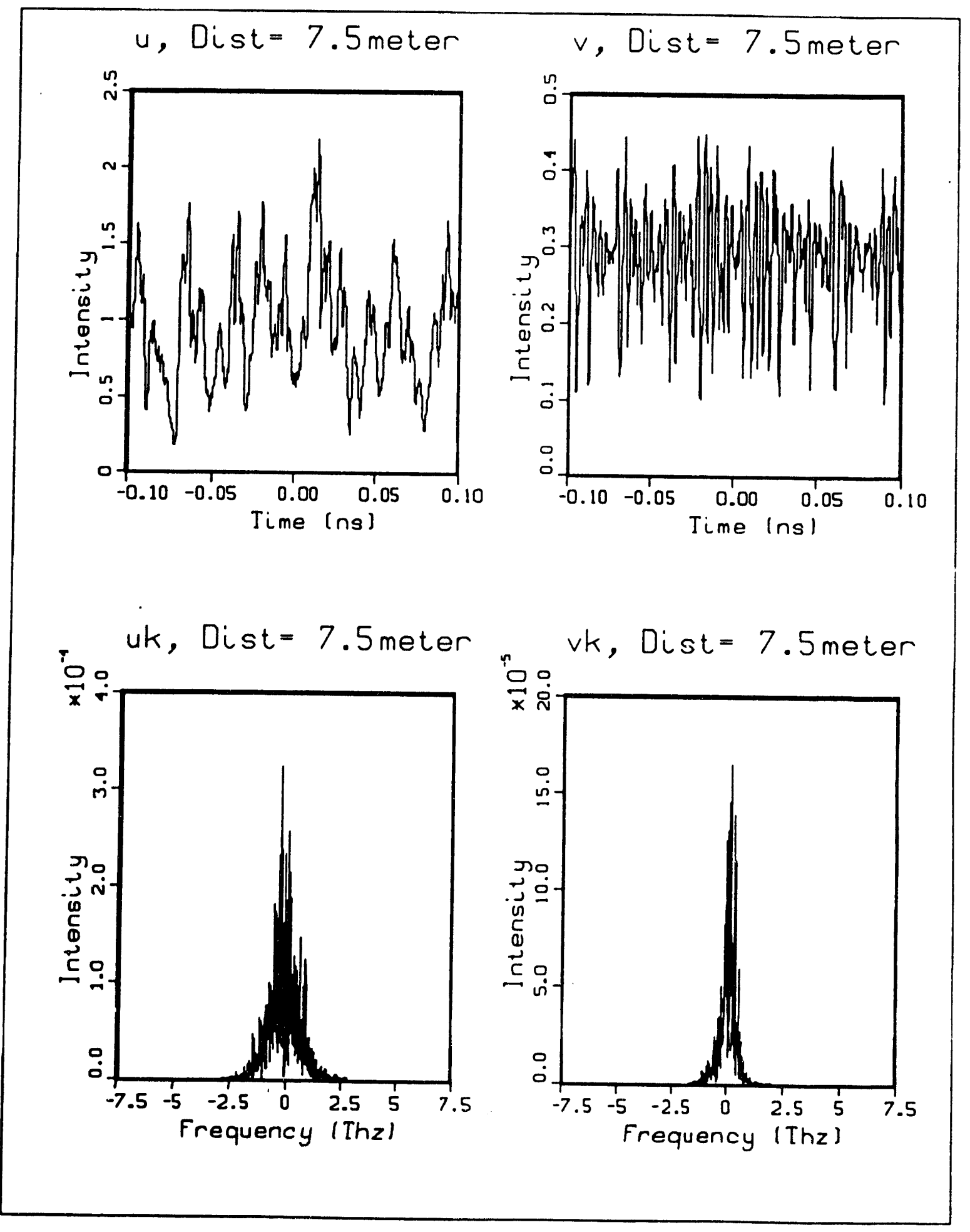




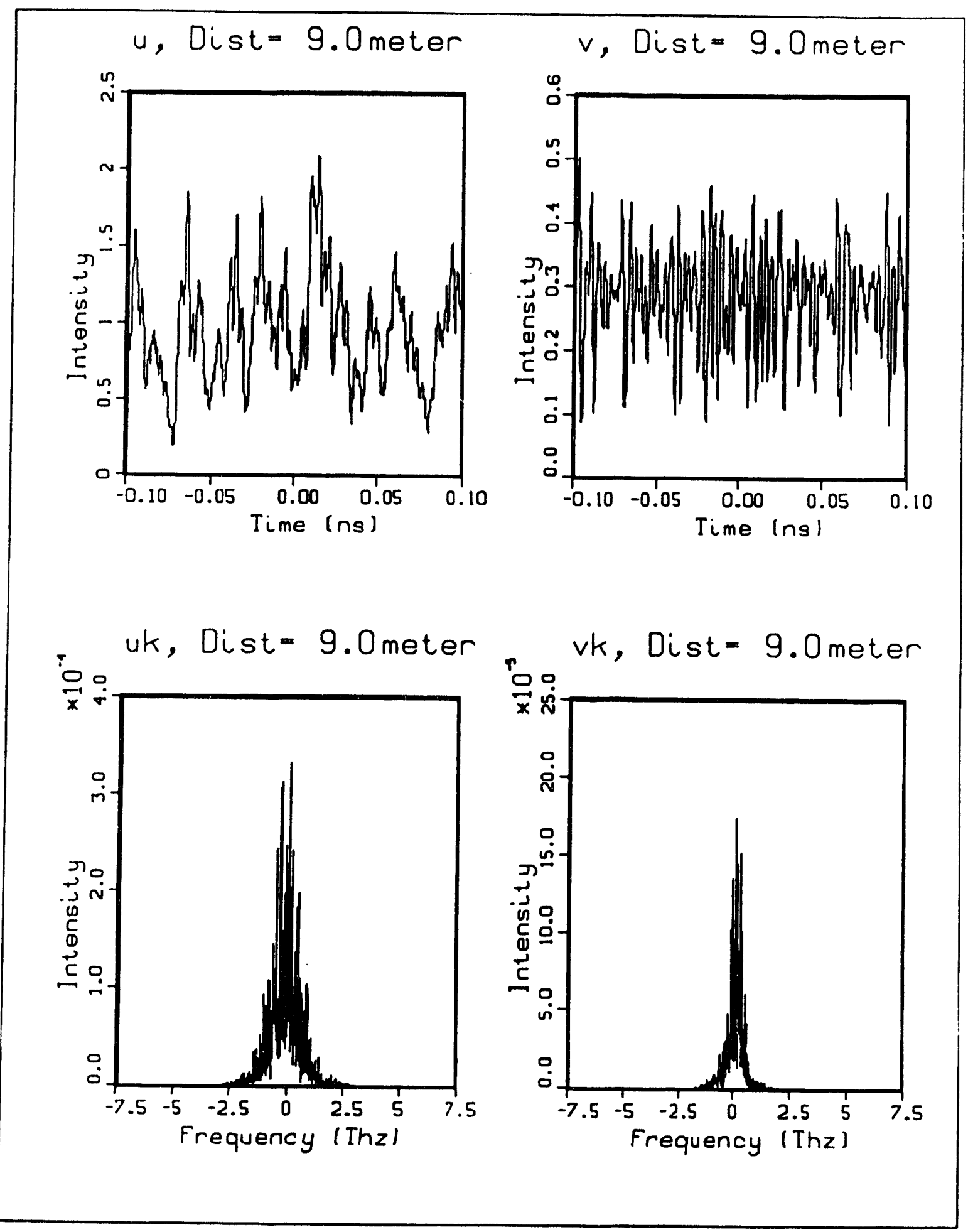




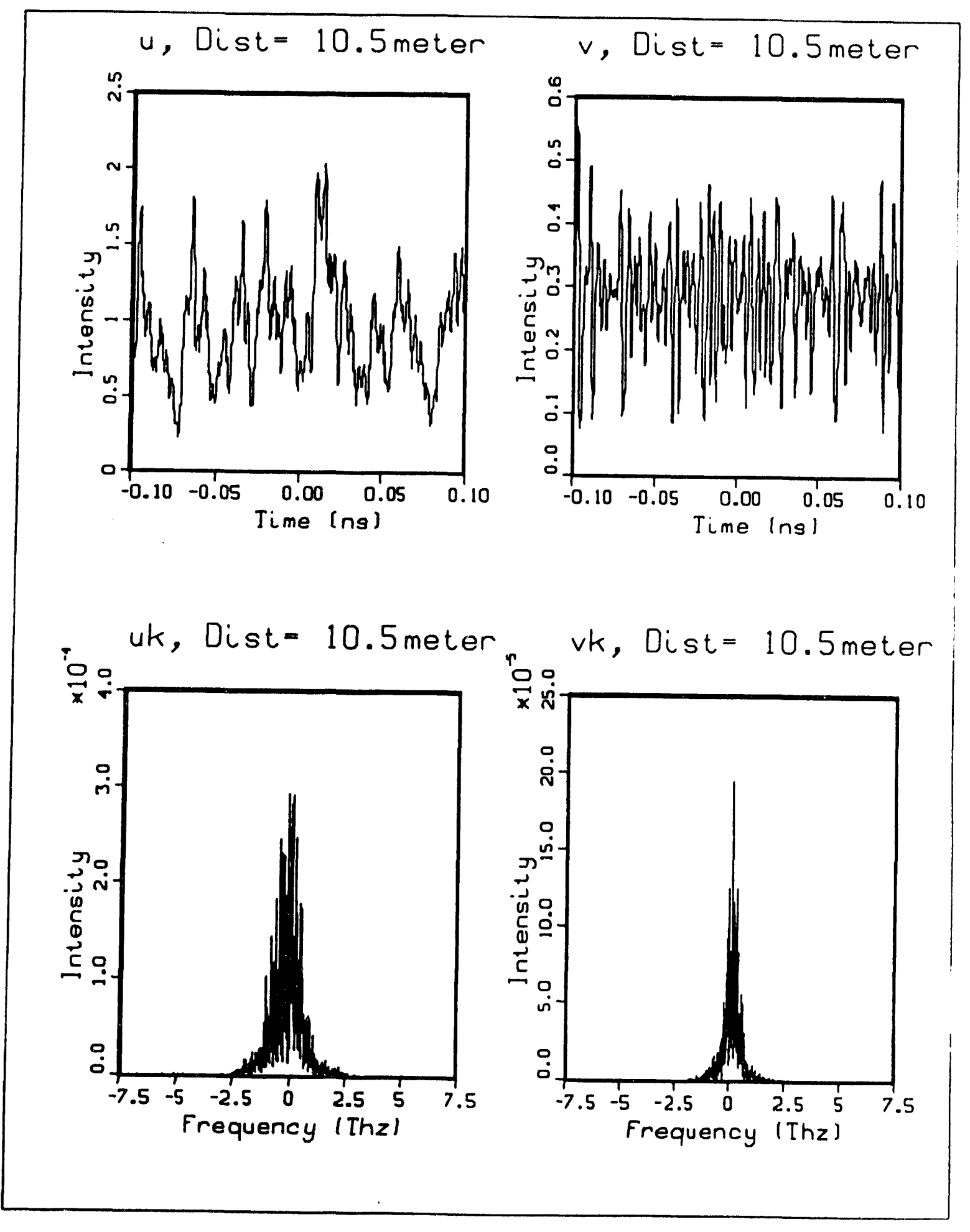



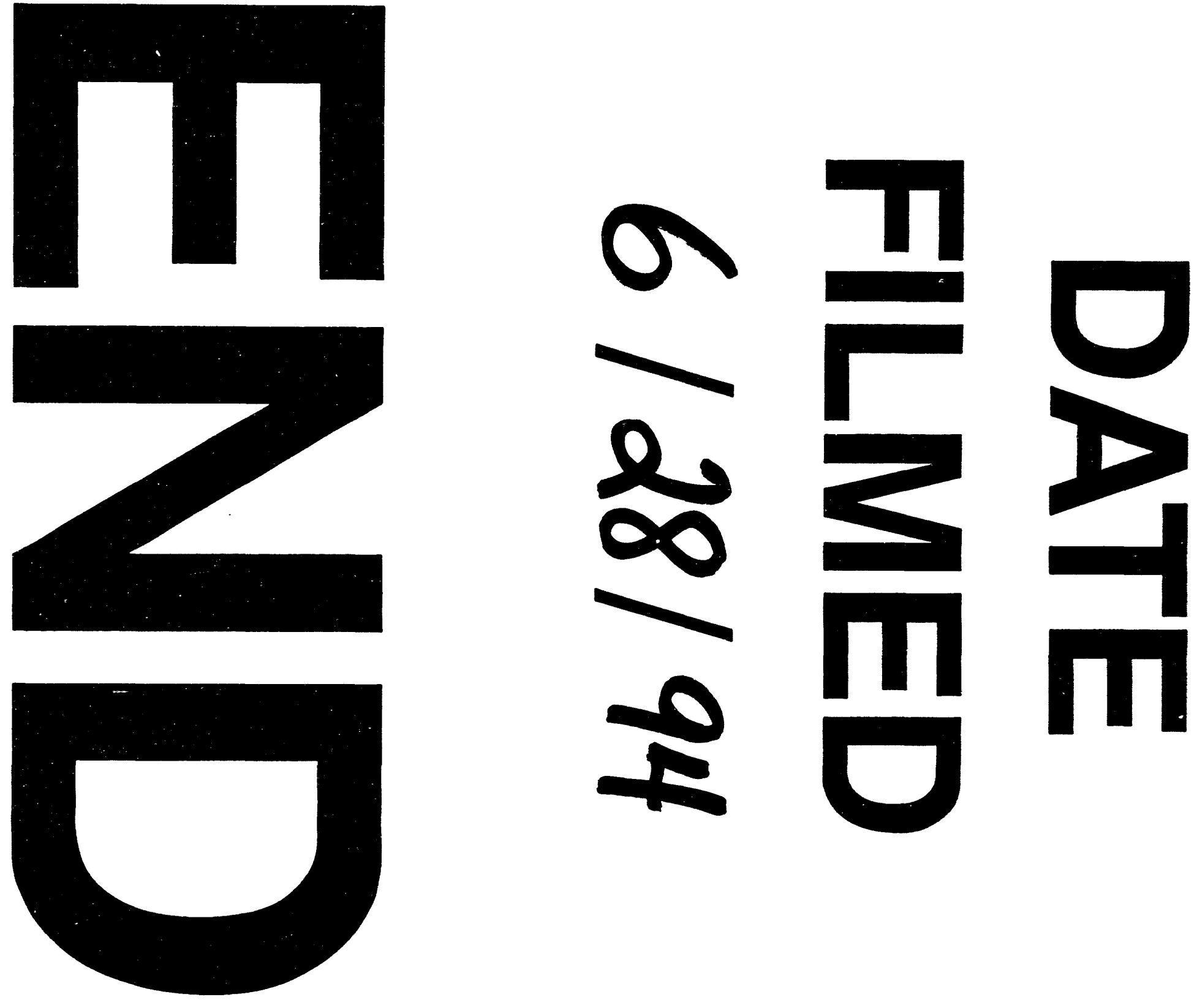
